\title{
Line-of-Credit Payment Scheme and Its Impact on the Retailer's Ordering Policy with Inventory-Level-Dependent Demand
}

\author{
Tao Jia, ${ }^{1,2}$ Feng Lin, ${ }^{1}$ Zhengwen He, ${ }^{1,2}$ and Nengmin Wang ${ }^{1,2}$ \\ ${ }^{1}$ School of Management, Xian Jiaotong University, Xian 710049, China \\ ${ }^{2}$ The Key Lab of the Ministry of Education for Process Control \& Efficiency Engineering, Xian 710049, China \\ Correspondence should be addressed to Feng Lin; lfxddz@stu.xjtu.edu.cn
}

Received 1 February 2016; Accepted 6 June 2016

Academic Editor: Rita Gamberini

Copyright (c) 2016 Tao Jia et al. This is an open access article distributed under the Creative Commons Attribution License, which permits unrestricted use, distribution, and reproduction in any medium, provided the original work is properly cited.

\begin{abstract}
Practically, the supplier frequently offers the retailer credit period to stimulate his/her ordering quantity. However, such creditperiod-only policy may lead to the dilemma that the supplier's account receivable increases with sale volume during delay period, especially for the item with inventory-level-dependent demand. Thus, a line-of-credit (LOC) payment scheme is usually adopted by the supplier for better controlling account receivables. In this paper, the two-parameter LOC clause is firstly applied to develop an economic order quantity (EOQ) model with inventory-level-dependent demand, aiming to explore its influences on the retailer's ordering policy. Under this new policy, the retailer will be granted full delay payment if his/her order quantity is below a predetermined quantity. Otherwise, the retailer should make immediate payment for the excess part. After analyzing the relationships among parameters, two distinct cases and several theoretical results can be derived. From numerical examples, two incentives, a longer credit period and a lower rate of the retailer's capital opportunity cost, should account for the retailer's excessive ordering policy. And a well-designed LOC clause can be applied to induce the retailer to place an appropriate ordering quantity and ensure the supplier maintains a reasonable account receivable.
\end{abstract}

\section{Introduction}

Faced with a time of decreasing profit margins, enterprises in physical distribution channel attach more and more importance to adoption of proper trade credit policies. Under such policies, the supplier offers the retailer a certain credit period without interest in order to attract more retailers and stimulate sales. It appeals to retailers when they are lacking capital. And for the supplier, it can not only promote sales but also decrease on-hand inventories to gain more profits. Taking Walmart China as an example, the delay period in paying for fresh foods is usually 14 days and for packaged foods is 45 days. And Wilson and Summers [1] suggested that more than $80 \%$ of B2B transactions in the United Kingdom are completed via trade credit.

Since Goyal [2] firstly developed an EOQ model with permissible delay in payments, considerable research has been done to explore the benefit of credit period towards the retailer's ordering policy. As Giri and Maiti [3] mentioned, the retailer orders more quantities after introducing the delay payment and it is desirable from the supplier's point of view. Until recently, however, some adverse effects of trade credit policy have been identified and reported in the literature. As Teng et al. [4] noted, for example, a longer credit period may increase the supplier's opportunity cost and trigger the retailer's default risk. In real business environment, the supplier usually supplies the item to multiple retailers. Offering every retailer credit period may lead to the sharp increase of the supplier's account receivable and cause considerable pressure on his/her cash flow. To deal with this problem, an easy-to-use strategy has been adopted in the physical distribution channel (e.g., for Fast Moving Consumer Goods). In this strategy, an upper limit for the account payable of the retailer is set by the supplier and the retailer should make the cash payment for the excess purchases immediately after ordering items. However, little attention has been given to this widely adopted strategy in the related research. Hence, in this paper we propose a new payment scheme of LOC to redetermine the retailer's optimal ordering policy under the single item scenario 
in the framework of the deterministic EOQ inventory model.

In the recent two decades, plenty of work has been devoted to extending the inventory model with trade credit to various dimensions. Jamal et al. [5] developed a generalized mathematical model by extending Goyal [2] model to allow for shortages. Ouyang et al. [6] considered an inventory model for noninstantaneous deteriorating item under delay in payments. Geetha and Uthayakumar [7] determined the optimal replenishment policy for noninstantaneous deteriorating items by offering the retailer credit period with shortages and partial backlogging. Liao et al. [8] studied a two-warehouse inventory model for deteriorating items with two-level delay in payments. Pal et al. [9] investigated the optimal ordering policy and the optimal production rate under three-level trade credit of supplier-manufacturerretailer supply chain. Molamohamadi et al. [10] obtained the replenishment decision of a manufacturer under the economic production quantity $(\mathrm{EPQ})$ inventory model with backorder, assuming that the manufacturer delays paying for the received goods from the supplier and items start deteriorating as soon as they are being produced.

Recently, many researchers incorporate the condition of order quantity into the credit term to develop inventory models under delay in payments. Specifically, as long as the retailer's order quantity is greater than or equal to a predetermined quantity, the supplier is willing to offer him/her a fixed credit period. Chung et al. [11] considered the economic order quantity of the retailer under delay in payments depending on the ordering quantity. Chang et al. [12] presented the optimal policy for an integrated vendor-buyer inventory system when trade credit linked to the order quantity, assuming that the demand is a decreasing function of the retail price. Kreng and Tan [13] proposed the optimal replenishment policies under two levels of trade credit policy linked to the order quantity. Liang and Zhou [14] formulated a two-warehouse inventory model for deteriorating item with constant demand rate under conditionally permissible delay in payments to find the optimal replenishment policy. Taking the deteriorating item with expiration dates into account, Wu et al. [15] discussed the retailer's optimal credit period and lot-size policies under two-level trade credit financing. Under order-linked credit period and cash discount offered by the supplier, Shah and Cardenas-Barron [16] addressed the retailer's optimal ordering and credit policies for deteriorating items.

In the aforementioned literature, all researchers dealing with the EOQ models in the presence of delay in payments assume that the retailer obtains $100 \%$ delay payment as long as he/she orders a sufficient quantity. Otherwise, the supplier would not grant the retailer trade credit (i.e., 0\% delay payment). However, the supplier can relax this extreme case and proposes partial delay payment. That is, if the retailer's ordering quantity is less than a predetermined quantity, the retailer is allowed to delay $\alpha \%(0 \leq \alpha \leq 100)$ payment while the rest of purchases are required to be paid off immediately. Huang [17] combined conditionally delay in payments with partial delay in payments, dealing with optimal ordering policy of the retailer. Ouyang et al. [18] formulated an economic order quantity model for deteriorating item with partially permissible delay in payments linked to order quantity while the deteriorating rate is constant. Ouyang et al. [19] formulated a profit maximization EOQ model to extend Huang [17] model to consider defective item. Chen et al. [20] proposed an EPQ model for deteriorating item in a supply chain with upstream full trade credit and downstream partial trade credit. Wu et al. [21] constructed a supplierretailer-customer chain system for deteriorating items with maximum lifetime under upstream full trade credit and downstream partial trade credit.

All above deterministic EOQ inventory models are aimed at developing the retailer's optimal ordering policy for a fixed credit period, in which the credit term linked to ordering quantity merely acts as a lever to stimulate the retailer's ordering quantity. As mentioned above, although the offer of delay in payments contributes to reduce the supplier's onhand inventory, it may also have some negative impacts on the supplier's working capital. Besides Teng et al. [4], Lou and Wang [22] also suggested that trade credit may not only cause the loss of capital opportunity during the credit period but also increase the retailer's default risk. Unlike the scenario of single retailer in the literature, in practice a supplier normally needs to supply multiple retailers with multiple items. By this token, the policy of granting credit terms to all retailers may intensify the supplier's cash-flow pressure even under the deterministic demand rate scenario.

Similar to bank credit line, which is used to cap the credit size to avoid potential moral hazard and substantial financial risks when banks grant loans to retailers (Petersen and Rajan [23]), in the field of trade credit, Cai et al. [24] assumed that the supplier would set credit limits to optimally cap the retailer's lending against his/her account receivables. Burkart and Ellingsen [25] noted that the lending cap (line of credit) can be explained as a response to the problem of reckless trade credit. And in the physical goods distribution channel, the two-parameter LOC clause is often attached by the supplier to credit period policy for better controlling the account receivable from the retailer. Specifically, the value of LOC is a predetermined quota of the retailer's account payable for all kinds of items ordered from the supplier below which a full delay payment period can be granted to the retailer by the supplier. And if the LOC is exceeded, the retailer is required to make immediate cash payment for the excess part of the purchases. For instance, in a prefecture-level city located in eastern China, a distributor of Yili, which is one of the wellknown milk powder suppliers in China, would grant his/her downstream retailers one month credit for total amount of no more than thirty thousand dollars (LOC). That is, as long as the account payable from the retailer does not exceed thirty thousand dollars, the retailer can order any kinds of milk powders for any quantity and all products can be delayed payment for one month. Otherwise, the retailer should pay off the purchases exceeding thirty thousand dollars (LOC) immediately.

In the real business environment, an interesting phenomenon is observed in which the demand rate of many items depends on their inventory level (i.e., inventory-leveldependent demand rate), such as grocery industry and Fast Moving Consumer Goods. That is, due to the selective effect 
and advertising effect of the items in stock, the demand rate is assumed to be an increasing function of the retailer's inventory level (Urban [26]). Based on various assumptions of the related papers, the inventory-level-dependent demand rate models can be divided into two types. One is instantaneouslevel-dependent demand, such as the model built by Baker and Urban [27]. Another is initial inventory dependent demand proposed by Wang and Gerchak [28]. To capture the demand-stimulating effect of inventories, the assumption of instantaneous-level-dependent demand attracts more attention in the inventory-level-dependent demand literature (Balakrishnan et al. [29]). And the linear demand rate is one of the common used formulations, which can ensure that the demand rate decreases as the inventory level decreases with diminishing returns (Urban [26]). So far, considerable relevant works have been conducted to study the optimal operational strategies of the supply chain. Wu et al. [30] considered the problem of determining the optimal replenishment policy for noninstantaneous deteriorating item with stock-dependent demand. Chang et al. [31] extended Wu et al. [30] by assuming that most of the retail outlets have limited shelf space. Ghiami et al. [32] investigated a two-echelon supply chain model for a deteriorating item, in which the demand rate of retailer is stock-dependent while the retailer's warehouse has a limited capacity.

As Soni [33] mentioned, when the demand rate is inventory-level-sensitive, the retailer would be more inclined to keep higher inventory level to stimulate market demand and gain more profit. It implies that the retailer's inventory policy and market decision are mutually interactive under the circumstance. Furthermore, in practice, when the retailer has the initiative to accumulate more inventories, the policy of offering the retailer a fixed credit period would exert unexpected influences on the supplier's business performance. On the one hand, the rising order from the retailer consumes the supplier's on-hand inventory to gain more revenue. On the other hand, for given fixed credit period, the higher the item's demand rate is, the more the account receivable of the supplier is, leading him/her to the dilemma that higher sales volume is accompanied by higher cash-flow pressure. However, although considerable attention has been paid to study the retailer's ordering policy with inventory-level-dependent demand under trade credit, few of them take the perspective of the supplier to focus on his/her cash-flow pressure. Liao et al. [34] studied the inventory model with initial-stock-dependent consumption rate under delay in payments, aiming to solve the optimal replenishment policy for deteriorating item under inflation. Considering instantaneous inventory dependent demand, Min et al. [35] came up with the model for deteriorating item under two-level trade credit. Min et al. [36] developed an inventory model for exponentially deteriorating item under conditions of permissible delay in payments, assuming that the item is replenished at a finite rate and the demand rate of the item is dependent on the current inventory level. Therefore, when the retailer is stimulated to adopt an excessive ordering policy, it is essential to apply the twoparameter LOC clause to reconsider the retailer's ordering decision.
On this background, this paper employs the twoparameter LOC clause to develop an EOQ model with inventory-level-dependent demand for determining the optimal ordering policy of the retailer. The reason for choosing the EOQ model lies in two aspects: (i) as Cárdenas-Barrón et al. [37] noted, the EOQ model is arguably the simplest and most robust inventory model; (ii) the new policy can be regarded as a special form of conditionally permissible delay in payments policy, which is extensively studied through the EOQ-based inventory model. More precisely, in this paper the two-parameter LOC clause is represented as a reversed partial delay payment policy under the single item scenario, and it reveals a more practical management context.

To sum up, the primary characteristics of our model can be listed below: (i) a new payment scheme linked to ordering quantity (i.e., line of credit) is firstly applied to the deterministic EOQ inventory model; (ii) two other incentives, a longer credit period and a lower rate of capital opportunity cost of the retailer, have been identified that can lead the retailer to order excessive quantity; and (iii) LOC payment scheme is applied to induce the retailer to place an appropriate ordering quantity and maintain a reasonable account payable.

The remainder of the paper is organized in the following structure. In Section 2, the notations and assumptions, which are used throughout the paper, are established. The mathematical model is formulated in Section 3 to maximize the annual profit of the retailer. In Section 4, we develop some useful lemmas and theorems to determine the retailer's optimal replenishment policy. Numerical examples and sensitivity analyses are provided in Section 5. Conclusions and managerial insights are given in Section 6, and some promising directions for applying the new policy are also presented.

\section{Notations and Assumptions}

The following notations are used throughout the paper to develop the mathematical model:

$A$ : ordering cost per order,

$h$ : holding cost per unit per year (excluding interest charges),

$p$ : selling price per unit,

$c$ : purchasing cost per unit,

$M$ : the credit period, which should be positive,

$I_{k}$ : the interest charged per dollar in stock per year, that is, the rate of capital opportunity cost of the retailer,

$I_{e}$ : the interest earned per dollar per year,

$T$ : the length of replenishment cycle time (decision variable),

$t$ : the time point within the retailer's ordering cycle, where $t \in[0, T]$,

$i(t)$ : the instantaneous inventory level of the retailer,

Q: the retailer's order quantity per cycle, 
$Q_{1}$ : the upper limit of quantity at which the full delay payment is permitted per order,

$T_{1}$ : the time interval in which $Q_{1}$ units of the item are depleted to zero due to the demand,

$T_{0}$ : the time interval it takes for the retailer's inventory level to decline from $Q$ to a predetermined quantity $Q_{1}$,

$\Pi(T)$ : the retailer's annual profit function,

$T^{*}$ : the optimal cycle time of the retailer,

$Q^{*}$ : the optimal ordering quantity of the retailer.

The following assumptions are adopted throughout the paper. Except two-parameter LOC clause (i.e., the fourth and the fifth assumptions), the second assumption can be referred to in Mo et al. [38] and others are similar to those in Huang [17].

(1) The replenishment rate is infinite and shortages are not allowed.

(2) Similar to Ghiami et al. [32], the demand rate $D(t)$ is a known function of the retailer's instantaneous inventory level $i(t)$, which is given by $D(t)=a+b i(t)$, where $a$ and $b$ are positive constants while $a \gg b$. In this model, $a$ is a scaling parameter and $b$ represents the inventory elasticity of demand.

(3) The inventory system involves only one type of item.

(4) At each ordering cycle, if $Q \leq Q_{1}$, the retailer is offered the full delay payment of $M$ periods. During the time interval $[M, T]$, the retailer should bear the opportunity cost of capital for the item in stock, which is due to the cash payment at the end of credit period $M$. That is, the retailer should pay for the interest charged on the item in stock with the rate $I_{k}$ after credit period $M$.

(5) At each ordering cycle, if $Q>Q_{1}$, the reversed partial delay payment (i.e., LOC clause) is permitted. That is, the retailer is allowed to pay $c Q_{1}$ after $M$ time periods while he/she should make a partial payment of $c(Q-$ $Q_{1}$ ) to the supplier when he/she places the order. This assumption constitutes the major difference of the proposed model from previous papers.

(6) The retailer can accumulate revenue and earn interest from the beginning that his/her customers pay for the amount of purchases to the retailer until the end of the credit period offered by the supplier. That is, the retailer can accumulate revenue to earn interest at a rate of $I_{e}$ during the credit period.

\section{Mathematical Formulation of the Model}

According to the above assumptions, the inventory model goes as follows. The inventory level of the retailer is $Q$ units of the item at the beginning of each replenishment cycle (e.g., the time point $T=0$ ). And it decreases gradually with the demand rate $a+b i(t)$ in the time interval $[0, T]$. At $t=T$, the inventory level drops to zero, and the depletion process of the retailer's on-hand inventory repeats following the same pattern.

During the time interval $[0, T]$, the variation of the inventory level $i(t)$ can be represented by the following differential equation:

$$
\frac{\mathrm{d} i(t)}{\mathrm{d} t}=-a-b i(t), \quad 0 \leq t \leq T .
$$

With the boundary condition $i(0)=Q$, the solution of (1) is

$$
i(t)=\left(Q+\frac{a}{b}\right) e^{-b t}-\frac{a}{b}, \quad 0 \leq t \leq T .
$$

And when $t$ equals $T$, the boundary condition $i(T)=0$ can be obtained. Then, substituting it into (2) leads to

$$
Q=\frac{a}{b} e^{b T}-\frac{a}{b} .
$$

Putting (3) into (2), the relationship between the retailer's instantaneous inventory level $i(T)$ and the replenishment cycle $T$ can be expressed as follows:

$$
i(t)=\frac{a}{b} e^{b(T-t)}-\frac{a}{b}, \quad 0 \leq t \leq T .
$$

Thus, the demand rate $D(t)$ can be given by

$$
D(t)=a+b\left[\frac{a}{b} e^{b(T-t)}-\frac{a}{b}\right]=a e^{b(T-t)}, \quad 0 \leq t \leq T .
$$

When the order quantity of the retailer equals the predetermined quantity $Q_{1}, i(0)=Q_{1}$ is put into (4) leading to

$$
T_{1}=\frac{1}{b} \ln \left(\frac{b}{a} Q_{1}+1\right) .
$$

Accordingly, $T_{1}$ is the critical value to determine whether the retailer is offered the full delay in payments or not. If $Q \leq Q_{1}$ (i.e., $T \leq T_{1}$ ), then the retailer is offered the full delay payment of $M$ periods, which is similar to previous models. Otherwise, LOC clause comes into effect, and only the amount that equals $Q_{1}$ is allowed to be delayed in payments while the rest of the items should be paid off immediately. Under the circumstance, $i\left(T_{0}\right)=Q_{1}$ is put into (4) leading to

$$
T_{0}=T-\frac{1}{b} \ln \left(\frac{b}{a} Q_{1}+1\right)=T-T_{1} .
$$

That is, it takes time period of $T_{0}$ for the inventory level of the retailer to decline from $Q$ units to the predetermined quantity $Q_{1}$. The above descriptions are illustrated in Figure 1 .

In the context of LOC payment scheme offered by the supplier, we have formulated the calculation of the retailer's instantaneous inventory level. And we will take the retailer's perspective to develop his/her annual profit function $\Pi(T)$ under different cases. The key to classify $\Pi(T)$ lies in the formations of the retailer's annual opportunity cost of capital. For a retailer, he/she may bear not only the interest on the item incurred immediate payment which is determined by $Q_{1}$ (i.e., $T_{1}$ ) but also the interest for the item still in stock after credit period $M$ (as indicated by the shaded area in Figure 1). 


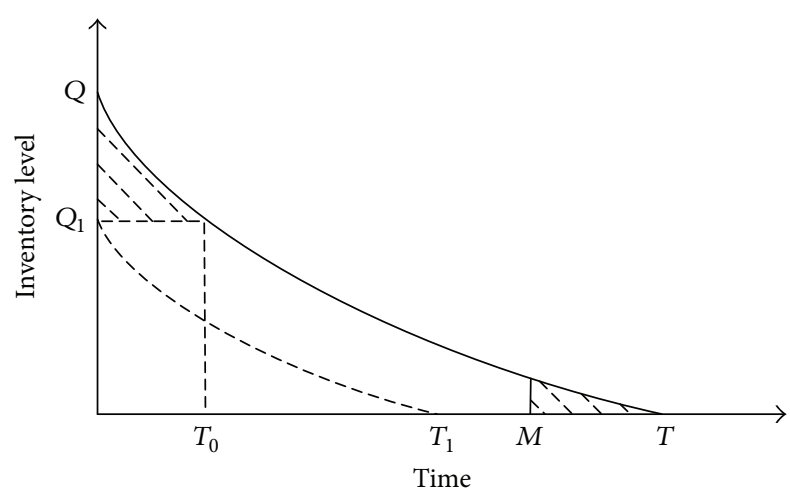

FIGURE 1: Graphical representation of LOC model.

The relationship between $T_{0}$ and $M$ differentiates whether there is an overlap of these two parts of interest, which may cause the change of the retailer's annual opportunity cost of capital. Comparing Figure 4(b) with Figure 5(b), we can clearly see that when $T_{0}>M$, the overlap will occur. Let $T_{0}=M$, and from (7), we have $T=T_{1}+M$. That is, other than $T_{1}$ and $M, T_{1}+M$ is also a significant factor to be considered in the classification of $\Pi(T)$.

To conclude, according to the values of parameters $M, T_{1}$, and $T_{1}+M$, there are two cases: (1) $M<T_{1} \leq T_{1}+M$ and (2) $T_{1} \leq M \leq T_{1}+M$. And taking into account the relationships between decision variable $T$ and three parameters, each case can fall into four subcases based on the retailer's different annual opportunity costs of capital. Therefore, the following category can be obtained.

Case $1\left(M<T_{1} \leq T_{1}+M\right)$. The elements comprising the annual profit function of the retailer are listed below.

(1) Holding cost (excluding interest charges) $=h \int_{0}^{T} i(t) \mathrm{d} t / T=h a\left(e^{b T}-1-b T\right) / b^{2} T$.

(2) Selling profit $=((p-c) / T) Q=((p-c) a / b T)\left(e^{b T}-1\right)$.

(3) Ordering cost $=A / T$.

(4) Based on the different relationships between $T$ and other parameters, four subcases should be considered in terms of the retailer's annual opportunity cost of capital.

(i) $T \leq M$, shown in Figure 2 .

In this subcase, the retailer obtains the full delay payment since the ordering quantity satisfies $Q \leq Q_{1}$. He/she can get the interest earned from sales revenue during the time interval $[0, M]$ and there is no interest charged on items in stock. Thus, the retailer's annual opportunity cost of capital

$$
\begin{aligned}
& =-\frac{p I_{e}}{T}\left[\int_{0}^{T} \int_{0}^{t} D(u) \mathrm{d} u \mathrm{~d} t+(M-T) Q\right] \\
& =-\frac{a p I_{e}}{b^{2} T}\left(e^{b T} b M-e^{b T}+1-b M+b T\right) .
\end{aligned}
$$

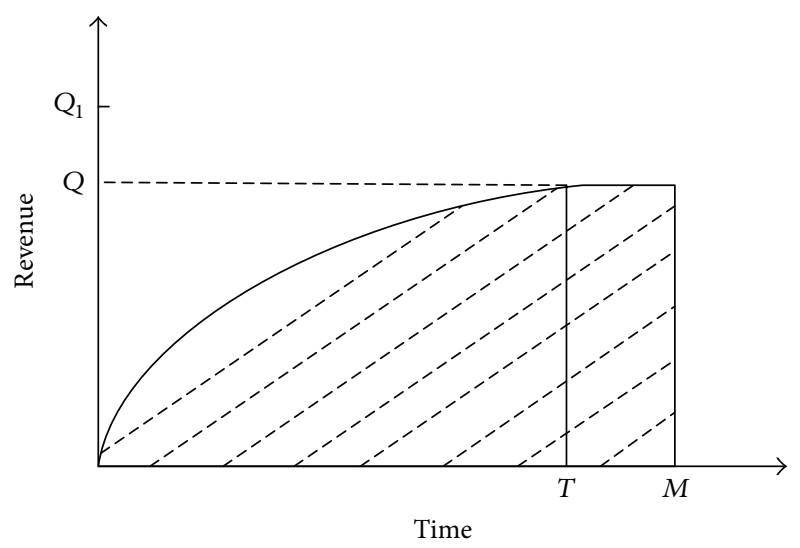

FIGURE 2: The retailer's annual opportunity cost of capital when $T \leq$ $M$.

(ii) $M \leq T \leq T_{1}$, shown in Figure 3 .

In this subcase, the retailer obtains the full delay payment since the ordering quantity satisfies $Q \leq Q_{1}$. He/she can get the interest of sales revenue during the time interval $[0, M]$ (see Figure 3(a)) but should pay the interest charged on items in stock during the time interval $[M, T]$ (see Figure 3(b)). Hence, the retailer's annual opportunity cost of capital

$$
\begin{aligned}
= & -\frac{p I_{e}}{T} \int_{0}^{M} \int_{0}^{t} D(u) \mathrm{d} u \mathrm{~d} t+\frac{c I_{k}}{T} \int_{M}^{T} i(t) \mathrm{d} t \\
= & -\frac{a p I_{e} e^{b T}}{b^{2} T}\left(e^{-b M}+b M-1\right) \\
& +\frac{a c I_{k}\left[e^{-b(M-T)}+b M-1-b T\right]}{b^{2} T} .
\end{aligned}
$$

(iii) $T_{1} \leq T \leq T_{1}+M$, shown in Figure 4 .

In this subcase, since the ordering quantity satisfies $Q>Q_{1}$, the retailer obtains the reversed partial delay payment, and from Figure 4 it can be found that $T_{0}=T-T_{1} \leq M$. He/she can gain the interest earned from the sales revenue during the time interval $[0, M]$ (see Figure 4(a)). And the retailer should be charged the interest on the item of immediate payment during the time interval $\left[0, T_{0}\right]$ and pay the interest for the item of delayed payment still in stock from time $M$ to time $T$ (see Figure 4(b)). Hence, the retailer's annual opportunity cost of capital

$$
\begin{aligned}
= & -\frac{p I_{e}}{T} \int_{0}^{M} \int_{0}^{t} D(u) \mathrm{d} u \mathrm{~d} t+\frac{c I_{k}}{T}\left[\int_{0}^{T_{0}}\left(i(t)-Q_{1}\right) \mathrm{d} t\right. \\
& \left.+\int_{M}^{T} i(t) \mathrm{d} t\right] \\
= & -\frac{a p I_{e} e^{b T}}{b^{2} T}\left(e^{-b M}+b M-1\right)
\end{aligned}
$$




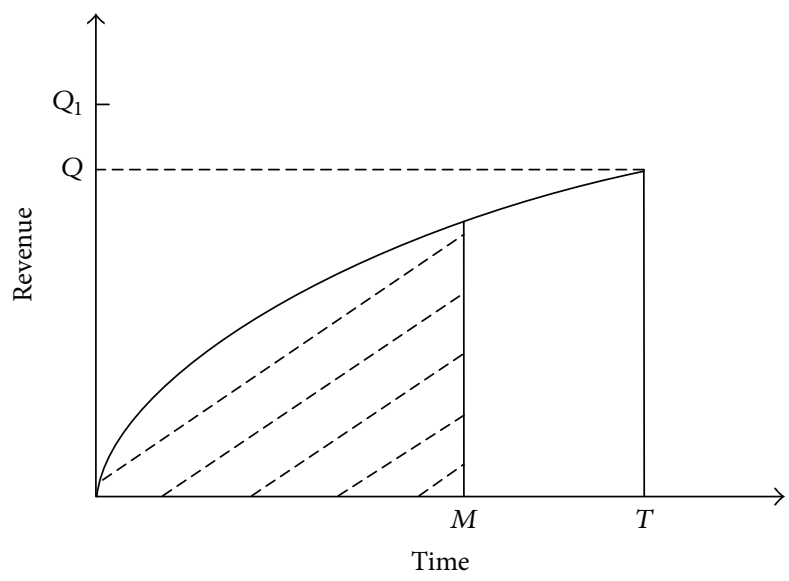

(a)

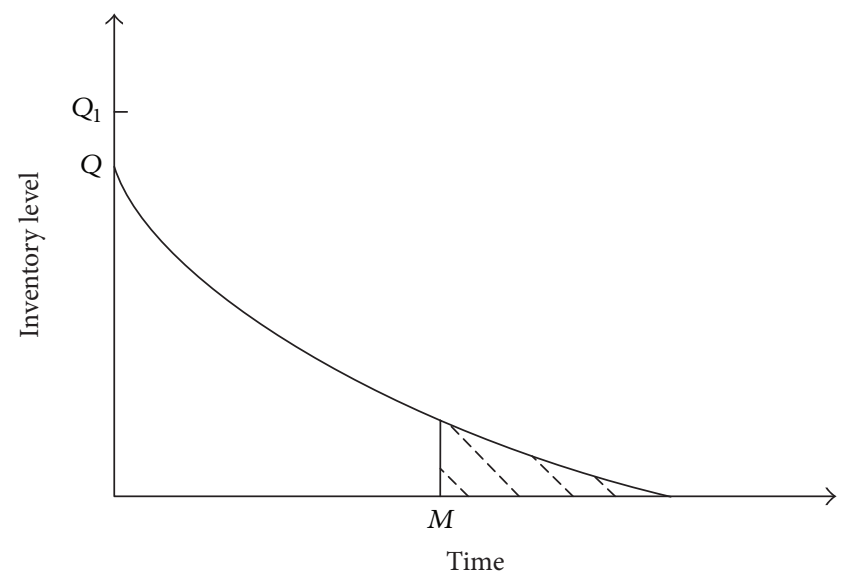

(b)

FIgURE 3: The retailer's annual opportunity cost of capital when $T_{1} \geq T \geq M$.

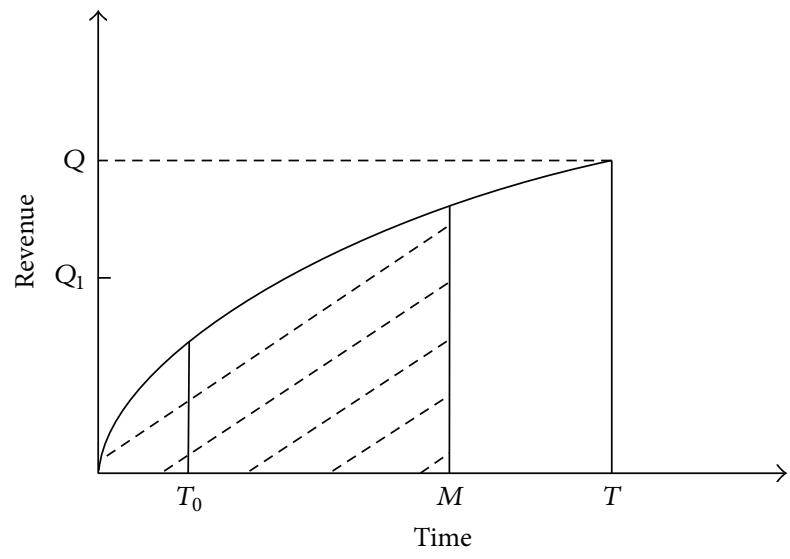

(a)

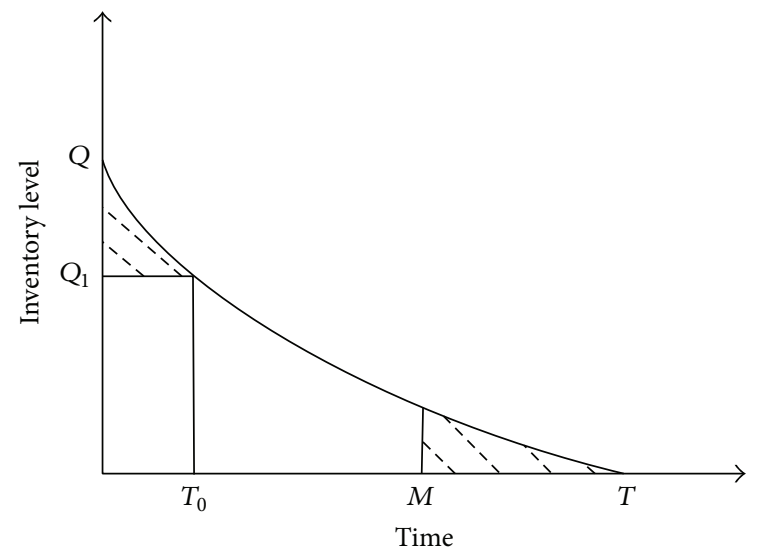

(b)

FIGURE 4: The retailer's annual opportunity cost of capital when $T_{1} \leq T \leq M+T_{1}$.

$+\frac{c I_{k}}{b^{2} T}\left[a\left(e^{b T}+e^{b T-b M}-e^{b T_{1}}-1\right)\right.$

$\left.+a b\left(T_{1}-2 T+M\right)-b^{2}\left(T-T_{1}\right) Q_{1}\right]$.

(iv) $T_{1}+M \leq T$, shown in Figure 5 .

In this subcase, the retailer obtains the partial delay payment since the ordering quantity satisfies $Q>Q_{1}$, and from Figure 5 it can be found that $T_{0}=T-T_{1} \geq M$. He/she can gain the interest earned from the sales revenue during the time interval $[0, M]$ (see Figure 5(a)). Meantime, the retailer should be charged the interest on the item of immediate payment during the time interval $\left[0, T_{0}\right]$ and pay the interest for the item of delayed payment still in stock from the time $M$ to time $T$ (see Figure 5(b)). Thus, the retailer's annual opportunity cost of capital

$$
\begin{aligned}
= & -\frac{p I_{e}}{T} \int_{0}^{M} \int_{0}^{t} D(u) \mathrm{d} u \mathrm{~d} t \\
& +\frac{c I_{k}}{T}\left[\int_{0}^{M}\left(i(t)-Q_{1}\right) \mathrm{d} t+\int_{M}^{T} i(t) \mathrm{d} t\right] \\
= & -\frac{a p I_{e} e^{b T}}{b^{2} T}\left(e^{-b M}+b M-1\right) \\
& +\frac{c I_{k}}{b^{2} T}\left(a e^{b T}-b^{2} M Q_{1}-a-a b T\right) .
\end{aligned}
$$


From the above arguments, the annual profit function for the retailer can be expressed as $\Pi(T)=$ -holdingcost + selling profit - ordering cost - annual opportunity cost of capital. And all of the subcases can be summarized as follows:

$$
\Pi(T)= \begin{cases}\Pi_{1}(T), & 0 \leq T \leq M, \\ \Pi_{2}(T), & M \leq T \leq T_{1}, \\ \Pi_{3}(T), & T_{1} \leq T \leq T_{1}+M, \\ \Pi_{4}(T), & T_{1}+M \leq T,\end{cases}
$$

where

$$
\begin{aligned}
\Pi_{1}(T)= & -\frac{h a\left(e^{b T}-1-b T\right)}{b^{2} T}+\frac{a(p-c)}{b T}\left(e^{b T}-1\right)-\frac{A}{T}+\frac{a p I_{e}}{b^{2} T}\left(e^{b T} b M-e^{b T}+1-b M+b T\right), \\
\Pi_{2}(T)=- & \frac{h a\left(e^{b T}-1-b T\right)}{b^{2} T}+\frac{a(p-c)}{b T}\left(e^{b T}-1\right)-\frac{A}{T}+\frac{a p I_{e} e^{b T}}{b^{2} T}\left(e^{-b M}+b M-1\right) \\
& -\frac{a c I_{k}}{b^{2} T}\left[e^{-b(M-T)}+b M-1-b T\right], \\
\Pi_{3}(T)= & -\frac{h a\left(e^{b T}-1-b T\right)}{b^{2} T}+\frac{a(p-c)\left(e^{b T}-1\right)}{b T}-\frac{A}{T}+\frac{a p I_{e} e^{b T}}{b^{2} T}\left(e^{-b M}+b M-1\right) \\
& -\frac{c I_{k}\left[a\left(e^{b T}+e^{b T-b M}-e^{b T_{1}}-1\right)+a b\left(T_{1}-2 T+M\right)-b^{2}\left(T-T_{1}\right) Q_{1}\right]}{b^{2} T}, \\
& -\frac{c I_{k}}{b^{2} T}\left(a e^{b T}-b^{2} M Q_{1}-a-a b T\right) . \\
\Pi_{4}(T)= & -\frac{h a\left(e^{b T}-1-b T\right)}{b^{2} T}+\frac{a(p-c)\left(e^{b T}-1\right)}{b T}-\frac{A}{T}+\frac{a p I_{e} e^{b T}}{b^{2} T}\left(e^{-b M}+b M-1\right)
\end{aligned}
$$

Since $\Pi_{1}(M)=\Pi_{2}(M), \Pi_{2}\left(T_{1}\right)=\Pi_{3}\left(T_{1}\right)$, and $\Pi_{3}\left(T_{1}+M\right)=$ $\Pi_{4}\left(T_{1}+M\right), \Pi(T)$ is continuous and well defined.

Case $2\left(T_{1} \leq M \leq T_{1}+M\right)$. In this case, the expressions of the holding cost, selling profit, and ordering cost are the same as those in Case 1. As for the retailer's annual opportunity cost of capital, there are four subcases which should be considered based on the various relationships between $T$ and other parameters.

(i) $T \leq T_{1}$.

In this subcase, the retailer's annual opportunity cost of capital has the similar form which is shown in Figure 2, so we omit it.

(ii) $T_{1} \leq T \leq M$, shown in Figure 6 .

In this subcase, the retailer obtains the reversed partial permissible delay in payments since the ordering quantity satisfies $Q>Q_{1}$. And he/she can gain the interest earned from the sales revenue during the time interval $[0, M]$ (see Figure 6(a)). Meantime, the retailer should be charged the interest of immediate partial payment during the time interval $\left[0, T_{0}\right]$ (see
Figure 6(b)). Thus, the retailer's annual opportunity cost of capital

$$
\begin{aligned}
= & -\frac{p I_{e}}{T}\left[\int_{0}^{T} \int_{0}^{t} D(u) \mathrm{d} u \mathrm{~d} t+(M-T) Q\right] \\
& +\frac{c I_{k}}{T} \int_{0}^{T_{0}}\left(i(t)-Q_{1}\right) \mathrm{d} t \\
= & -\frac{a p I_{e}\left(-e^{b T}+1+b M e^{b T}-b M+b T\right)}{T b^{2}} \\
& +\frac{c I_{k}\left[a\left(e^{b T}-e^{b T_{1}}\right)-\left(T-T_{1}\right)\left(a b+b^{2} Q_{1}\right)\right]}{b^{2} T} .
\end{aligned}
$$

(iii) $M \leq T \leq T_{1}+M$.

In this subcase, the retailer's annual opportunity cost of capital has the similar form which is shown in Figure 4, so we omit it.

(iv) $T_{1}+M \leq T$.

In this subcase, the retailer's annual opportunity cost of capital has the similar form which is shown in Figure 5, so we omit it. 


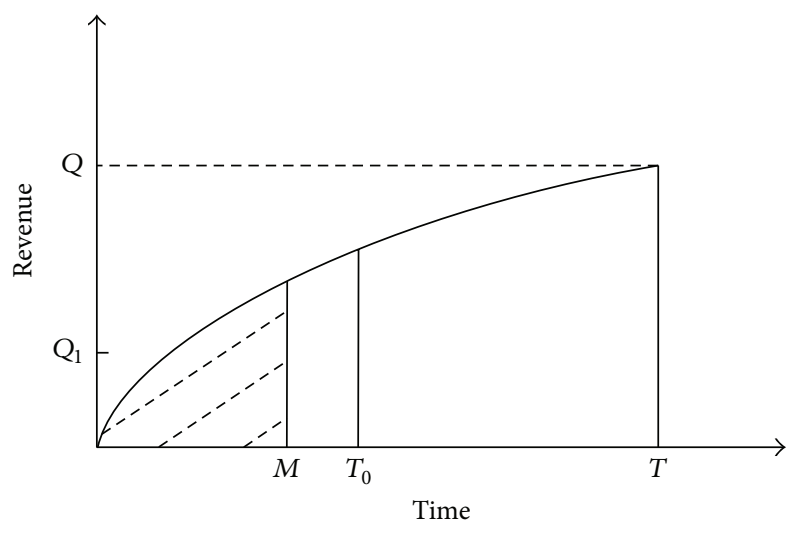

(a)

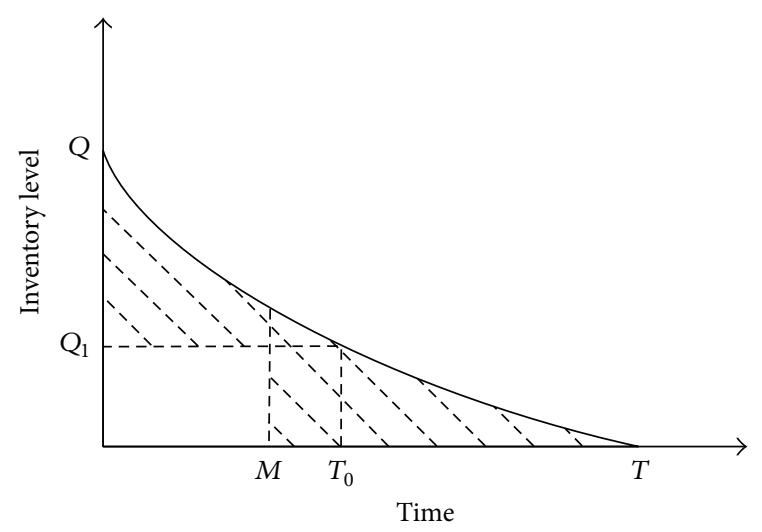

(b)

FIGURE 5: The retailer's annual opportunity cost of capital when $M+T_{1} \leq T$.

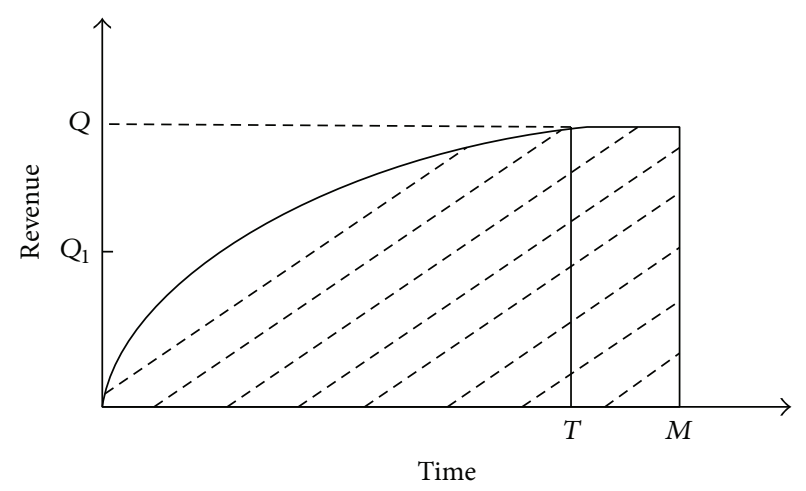

(a)

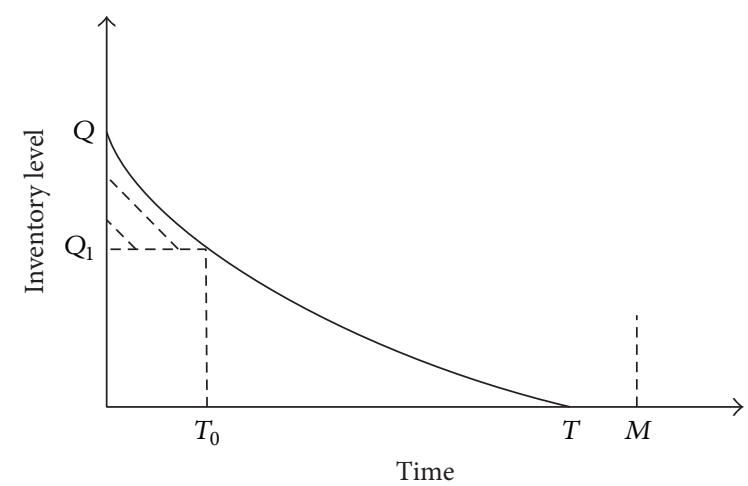

(b)

FIGURE 6: The retailer's annual opportunity cost of capital when $T_{1} \leq T \leq M$.

Similar to Case 1, the annual profit function of the retailer can be expressed as follows:

$$
\Pi(T)= \begin{cases}\Pi_{1}(T), & 0 \leq T \leq T_{1}, \\ \Pi_{5}(T), & T_{1} \leq T \leq M, \\ \Pi_{3}(T), & M \leq T \leq T_{1}+M, \\ \Pi_{4}(T), & T_{1}+M \leq T,\end{cases}
$$

where

$$
\begin{aligned}
\Pi_{5}(T) & \\
= & -\frac{h a\left(e^{b T}-1-b T\right)}{b^{2} T}+\frac{a(p-c)\left(e^{b T}-1\right)}{b T}-\frac{A}{T} \\
& +\frac{a p I_{e}\left(-e^{b T}+1+b M e^{b T}-b M+b T\right)}{T b^{2}} \\
& -\frac{c I_{k}\left[a\left(e^{b T}-e^{b T_{1}}\right)-\left(T-T_{1}\right)\left(a b+b^{2} Q_{1}\right)\right]}{b^{2} T} .
\end{aligned}
$$

Since $\Pi_{1}\left(T_{1}\right)=\Pi_{5}\left(T_{1}\right), \Pi_{5}(M)=\Pi_{3}(M)$, and $\Pi_{3}\left(T_{1}+M\right)=$ $\Pi_{4}\left(T_{1}+M\right), \Pi(T)$ is continuous and well defined.

\section{Theoretical Results}

The objective of this section is to determine the optimal replenishment cycle $T^{*}$ to maximize the retailer's annual profit. To obtain the retailer's global optimal solution, we should analyze the properties of $\Pi(T)$ in two cases, respectively.

Case $1\left(M<T_{1} \leq T_{1}+M\right)$. By taking the first derivative of $\Pi_{1}(T)$ in (13) with respect to $T$, we can obtain

$$
\frac{\mathrm{d} \Pi_{1}(T)}{\mathrm{d} T}=\frac{f_{1}(T)}{T^{2}}=\frac{1}{T^{2}}\left[\frac{a c_{12}(b T-1) e^{b T}}{b^{2}}-c_{13}\right],
$$

where

$$
\begin{aligned}
& c_{12}=p I_{e}(b M-1)+b p-h-b c, \\
& c_{13}=\frac{1}{b^{2}}\left[a(h-b p+b c)-b^{2} A+p I_{e} a(1-b M)\right] .
\end{aligned}
$$

As $\mathrm{d} f_{1}(T) / \mathrm{d} T=a c_{12} T e^{b T}$ and $f_{1}(0)=A>0$, then we have the following lemma to describe the property of $\Pi_{1}(T)$.

Lemma 1. For $T \in[0, M]$, the retailer's optimal ordering cycle can be given as in Table 1 . 
TABLE 1: The retailer's optimal ordering cycle for $T \in[0, M]$.

\begin{tabular}{lcc}
\hline Situations & Conditions & Optimal solutions \\
\hline \multirow{2}{*}{$c_{12}<0$} & $f_{1}(M)>0$ & $M$ \\
& $f_{1}(M) \leq 0$ & $T_{A}^{1}$ \\
\hline$c_{12} \geq 0$ & $/$ & $M$ \\
\hline Note: $T_{A}^{1} \in(0, M]$ and satisfies $f_{1}\left(T_{A}^{1}\right)=0$. &
\end{tabular}

Proof. See Appendix A for details.

Based on Lemma 1, it is apparent that when $c_{12}<0$ and $f_{1}(M) \leq 0, T_{A}^{1}$ is the unique maximum solution to $\Pi_{1}(T)$. On this occasion, it would be necessary to analyze the properties of the expression $f_{1}\left(T_{A}^{1}\right)=0$ to further explore the influence of the supplier's LOC clause towards the value of $T_{A}^{1}$, as shown in the following corollary.

Corollary 2. If $c_{12}<0$ and $f_{1}(M) \leq 0$, the value of $T_{A}^{1}$ is positively associated with the credit period $M$.

Proof. See Appendix B for details.

Similarly, taking the first derivative of $\Pi_{2}(T)$ in (14) with respect to $T$ will give

$$
\frac{\mathrm{d} \Pi_{2}(T)}{\mathrm{d} T}=\frac{f_{2}(T)}{T^{2}}=\frac{1}{T^{2}}\left[\frac{a c_{22}(b T-1) e^{b T}}{b^{2}}-c_{23}\right],
$$

where

$$
\begin{aligned}
& c_{22}=p I_{e}(b M-1)+b p-h-b c+\frac{p I_{e}-c I_{k}}{e^{b M}}, \\
& c_{23}=\frac{1}{b^{2}}\left[a(h-b p+b c)-b^{2} A+c I_{k} a(1-b M)\right] .
\end{aligned}
$$

As $\mathrm{d} f_{2}(T) / \mathrm{d} T=a c_{22} T e^{b T}$, we have the following lemma to describe the property of $\Pi_{2}(T)$.

Lemma 3. For $T \in\left[M, T_{1}\right]$, the retailer's optimal ordering cycle can be given as in Table 2.

Proof. See Appendix C for details.

Based on Lemma 3, it is obvious that when $c_{22}<0$, $f_{2}(M) \geq 0$, and $f_{2}\left(T_{1}\right) \leq 0, T_{A}^{2}$ is the unique maximum solution to $\Pi_{2}(T)$. By analyzing the properties of $f_{2}\left(T_{A}^{2}\right)=0$, we can obtain the following corollary to depict the variation of the value of $T_{A}^{2}$.

Corollary 4. If $c_{22}<0, f_{2}(M) \geq 0$, and $f_{2}\left(T_{1}\right) \leq 0$, the corollary in Table 3 can be obtained.

Proof. See Appendix D for details.

Similarly, taking the first-order derivative of $\Pi_{3}(T)$ in (15) with respect to $T$, the following expression can be obtained:

$$
\frac{\mathrm{d} \Pi_{3}(T)}{\mathrm{d} T}=\frac{f_{3}(T)}{T^{2}}=\frac{1}{T^{2}}\left[\frac{a c_{32}(b T-1) e^{b T}}{b^{2}}-c_{33}\right],
$$

TABLE 2: The retailer's optimal ordering cycle for $T \in\left[M, T_{1}\right]$.

\begin{tabular}{lcc}
\hline Situations & Conditions & Optimal solutions \\
\hline \multirow{4}{*}{$c_{22}<0$} & $f_{2}\left(T_{1}\right)>0$ & $T_{1}$ \\
& $f_{2}(M)<0$ & $M$ \\
& $f_{2}(M) \geq 0$ and $f_{2}\left(T_{1}\right) \leq 0$ & $T_{A}^{2}$ \\
\hline \multirow{2}{*}{$c_{22}>0$} & $f_{2}(M)>0$ & $T_{1}$ \\
& $f_{2}\left(T_{1}\right)<0$ & $M$ \\
& $f_{2}(M) \leq 0$ and $f_{2}\left(T_{1}\right) \geq 0$ & $T_{1}$ or $M$ \\
\hline \multirow{2}{*}{$c_{22}=0$} & $c_{23}>0$ & $M$ \\
& $c_{23}<0$ & $T_{1}$ \\
& $c_{23}=0$ & Any value on $\left[M, T_{1}\right]$ \\
\hline
\end{tabular}

Note: $T_{A}^{2} \in\left[M, T_{1}\right]$ and satisfies $f_{2}\left(T_{A}^{2}\right)=0$.

TABLE 3: The relationships between the retailer's optimal ordering cycle $T_{A}^{2}$ and LOC clause.

\begin{tabular}{lc}
\hline Situations & The relationship between $T_{A}^{2}$ and $M$ \\
\hline$g_{2}(M)>0$ & Positive \\
$g_{2}\left(T_{1}\right)<0$ & Negative \\
$g_{2}(M) \leq 0$ and $g_{2}\left(T_{1}\right) \geq 0$ & Negative for $T_{A}^{2} \in\left[M, T_{g}^{2}\right]$ and \\
& positive for $T_{A}^{2} \in\left[T_{g}^{2}, T_{1}\right]$ \\
\hline
\end{tabular}

Note: $T_{g}^{2} \in\left[M, T_{1}\right]$ and satisfies $g_{2}\left(T_{g}^{2}\right)=0$.

where

$$
\begin{aligned}
c_{32} & =p I_{e}(b M-1)+b p-h-b c-c I_{k}+\frac{p I_{e}-c I_{k}}{e^{M b}}, \\
c_{33} & =\frac{1}{b^{2}}[a(h-b p+b c) \\
& \left.+a c I_{k}\left(e^{b T_{1}}+1-b T_{1}-b M\right)-b^{2}\left(A+c I_{k} T_{1} Q_{1}\right)\right] .
\end{aligned}
$$

As $\mathrm{d} f_{3}(T) / \mathrm{d} T=a c_{32} T e^{b T}$, then we have the following lemma to describe the property of $\Pi_{3}(T)$.

Lemma 5. For $T \in\left[T_{1}, T_{1}+M\right]$, the retailer's optimal ordering cycle can be given as in Table 4.

Proof. The proof is similar to that of Lemma 3. Hence we omit it.

Based on Lemma 5, it is apparent that when $c_{32}<0$, $f_{3}\left(T_{1}\right) \geq 0$, and $f_{3}\left(T_{1}+M\right) \leq 0, T_{A}^{3}$ is the unique maximum solution to $\Pi_{3}(T)$. And by taking the first-order partial derivative of the expression $f_{3}\left(T_{A}^{3}\right)=0$ with respect to $M$ and $T_{1}$, respectively, we can obtain the following corollary.

Corollary 6. If $c_{32}<0, f_{3}\left(T_{1}\right) \geq 0$, and $f_{3}\left(T_{1}+M\right) \leq 0$, the corollary in Table 5 can be obtained.

Proof. The proof is similar to that of Corollary 4. Hence, we omit it. 
TABLE 4: The retailer's optimal ordering cycle for $T \in\left[T_{1}, T_{1}+M\right]$.

\begin{tabular}{ccc}
\hline Situations & Conditions & Optimal solutions \\
\hline \multirow{4}{*}{$c_{32}<0$} & $f_{3}\left(T_{1}+M\right)>0$ & $T_{1}+M$ \\
& $f_{3}\left(T_{1}\right)<0$ & $T_{1}$ \\
& $f_{3}\left(T_{1}\right) \geq 0$ and $f_{3}\left(T_{1}+M\right) \leq 0$ & $T_{A}^{3}$ \\
$c_{32}>0$ & $f_{3}\left(T_{1}\right)>0$ & $T_{1}+M$ \\
& $f_{3}\left(T_{1}+M\right)<0$ & $T_{1}$ \\
& $f_{3}\left(T_{1}\right) \leq 0$ and $f_{3}\left(T_{1}+M\right) \geq 0$ & $T_{1}$ or $T_{1}+M$ \\
$c_{32}=0$ & $c_{33}>0$ & $T_{1}$ \\
& $c_{33}<0$ & $T_{1}+M$ \\
\hline & $c_{33}=0$ & Any value on $\left[T_{1}, T_{1}+M\right]$
\end{tabular}

Note: $T_{A}^{3} \in\left[T_{1}, T_{1}+M\right]$ and satisfies $f_{3}\left(T_{A}^{3}\right)=0$.

Similarly, taking the first derivative of $\Pi_{4}(T)$ in (16) with respect to $T$, we can find

$$
\frac{\mathrm{d} \Pi_{4}(T)}{\mathrm{d} T}=\frac{f_{4}(T)}{T^{2}}=\frac{1}{T^{2}}\left[\frac{a c_{42}(b T-1) e^{b T}}{b^{2}}-c_{43}\right],
$$

where

$$
\begin{aligned}
& c_{42}=p I_{e}(b M-1)+b p-h-b c-c I_{k}+\frac{p I_{e}}{e^{M b}}, \\
& c_{43}=\frac{1}{b^{2}}\left[a(h-b p+b c)-b^{2} A+c I_{k}\left(a+b^{2} Q_{1} M\right)\right] .
\end{aligned}
$$

As $\mathrm{d} f_{4}(T) / \mathrm{d} T=a c_{42} T e^{b T}$, then we have the following lemma to describe the property of $\Pi_{4}(T)$.

Lemma 7. For $T \in\left[T_{1}+M,+\infty\right)$, the retailer's optimal ordering cycle can be given as in Table 6 .

Proof. The proof is similar to that of Lemma 3 except that $T$ is defined on $\left[T_{1}+M,+\infty\right)$ and the fact that $\lim _{T \rightarrow+\infty} f_{4}(T)=$ $+\infty$ or $\lim _{T \rightarrow+\infty} f_{4}(T)=-\infty$. Thus, we omit it.

Based on Lemma 7, it is apparent that when $c_{42}<0$ and $f_{4}\left(T_{1}+M\right) \geq 0, T_{A}^{4}$ is the unique maximum solution to $\Pi_{4}(T)$. And by taking the first-order partial derivative of $f_{4}\left(T_{A}^{4}\right)=$ 0 with respect to $M$ and $T_{1}$, respectively, we can obtain the following corollary.

Corollary 8. If $c_{42}<0$ and $f_{4}\left(T_{1}+M\right) \geq 0$, the corollary in Table 7 can be obtained.

Proof. The proof is similar to that of Corollary 4. Hence, we omit it.

Since $f_{1}(M)=f_{2}(M), f_{2}\left(T_{1}\right)=f_{3}\left(T_{1}\right)$, and $f_{3}\left(T_{1}+M\right)=$ $f_{4}\left(T_{1}+M\right)$, we let $\Delta_{1}=f_{1}(M)=f_{2}(M), \Delta_{2}=f_{2}\left(T_{1}\right)=$ $f_{3}\left(T_{1}\right)$, and $\Delta_{3}=f_{3}\left(T_{1}+M\right)=f_{4}\left(T_{1}+M\right)$. Considering that $c_{22}=c_{12}+\left(p I_{e}-c I_{k}\right) / e^{b M}, c_{32}=c_{22}-c I_{k}, c_{42}=c_{32}+$ $c I_{k} / e^{M b}, c_{42}=c_{22}-c I_{k}\left(1-e^{-M b}\right)$, and $f_{1}(0)>0$, we know that $c_{22}>c_{42}>c_{32}$. Consequently, by means of Lemmas 17 and multiple combinations of $\Delta_{1}, \Delta_{2}$, and $\Delta_{3}$, Theorem 9 can be obtained to determine the optimal cycle time $T^{*}$ for Case 1. For simplicity, we take the lower boundary of the time interval as $T^{*}$ when infinitely many optimal solutions exist.
Theorem 9. If $M<T_{1} \leq T_{1}+M$, the results in Table 8 can be obtained.

Case $2\left(T_{1} \leq M \leq T_{1}+M\right)$. Taking the first derivative of $\Pi_{1}(T)$ in (13) with respect to $T$ within the time interval $\left[0, T_{1}\right]$, we can easily obtain the lemma (corollary) the same as Lemma 1 (Corollary 2) except that the upper boundary of the time interval changes from $M$ to $T_{1}$. Hence, we omit it.

Similarly, taking the first derivative of $\Pi_{5}(T)$ in (19) with respect to $T$ will give

$$
\frac{\mathrm{d} \Pi_{5}(T)}{\mathrm{d} T}=\frac{f_{5}(T)}{T^{2}}=\frac{1}{T^{2}}\left[\frac{a c_{52}(b T-1) e^{b T}}{b^{2}}-c_{53}\right],
$$

where

$$
\begin{aligned}
c_{52} & =p I_{e}(b M-1)-c I_{k}+b p-h-b c, \\
c_{53} & =\frac{1}{b^{2}}\left[a(h-b p+b c)-b^{2}\left(A+c I_{k} Q_{1} T_{1}\right)\right. \\
& \left.+a p I_{e}(1-b M)+a c I_{k}\left(e^{b T_{1}}-b T_{1}\right)\right] .
\end{aligned}
$$

As $\mathrm{d} f_{5}(T) / \mathrm{d} T=a c_{52} T e^{b T}$, then we have the following lemma to describe the property of $\Pi_{5}(T)$.

Lemma 10. For $T \in\left[T_{1}, M\right]$, the retailer's optimal ordering cycle can be given as in Table 9.

Proof. The proof is similar to that in Lemma 3. Hence, we omit it.

Based on Lemma 10, it is apparent that when $c_{52}<0$, $f_{5}\left(T_{1}\right) \geq 0$, and $f_{5}(M) \leq 0, T_{A}^{5}$ is the unique maximum solution to $\Pi_{5}(T)$. And by taking the first-order partial derivative of $f_{5}\left(T_{A}^{5}\right)=0$ with respect to $M$ and $T_{1}$, respectively, we can obtain the following corollary.

Corollary 11. If $c_{52}<0, f_{5}\left(T_{1}\right) \geq 0$, and $f_{5}(M) \leq 0$,

(1) the value of $T_{A}^{5}$ is positively associated with $M$,

(2) the value of $T_{A}^{5}$ is positively associated with $T_{1}$.

Proof. The proof is similar to that of Corollary 2. Hence, we omit it.

Similarly, taking the first derivative of $\Pi_{3}(T)$ in (15) with respect to $T$ within the time interval $\left[M, T_{1}+M\right]$, we can easily obtain the lemma (corollary) the same as Lemma 5 (Corollary 6) except that the lower boundary of the time interval changes from $T_{1}$ to $M$. Hence, we omit it.

Likewise, taking the first derivative of $\Pi_{4}(T)$ in (16) with respect to $T$ within the time interval $\left[T_{1}+M,+\infty\right)$, we can obtain the lemma (corollary) the same as Lemma 7 (Corollary 8). Hence, we omit it.

Since $f_{1}\left(T_{1}\right)=f_{5}\left(T_{1}\right), f_{5}(M)=f_{3}(M)$, and $f_{3}\left(T_{1}+M\right)=$ $f_{4}\left(T_{1}+M\right)$, we let $\Delta_{4}=f_{1}\left(T_{1}\right)=f_{5}\left(T_{1}\right), \Delta_{5}=f_{5}(M)=$ $f_{3}(M)$, and $\Delta_{3}=f_{3}\left(T_{1}+M\right)=f_{4}\left(T_{1}+M\right)$. Considering $c_{52}=c_{12}-c I_{k}, c_{32}=c_{52}+\left(p I_{e}-c I_{k}\right) / e^{M b}, c_{42}=c_{32}+c I_{k} / e^{M b}$, $c_{42}=c_{52}+p I_{e} / e^{M b}$, and $f_{1}(0)>0$, we have $c_{12}>c_{52}, c_{42}>c_{52}$, 
TABLE 5: The relationships between the retailer's optimal ordering cycle $T_{A}^{3}$ and LOC clause.

\begin{tabular}{lcc}
\hline Situations & The relationship between $T_{A}^{3}$ and $M$ & The relationship between $T_{A}^{3}$ and $T_{1}$ \\
\hline$g_{3}\left(T_{1}\right)>0$ & Positive & Positive \\
$g_{3}\left(T_{1}+M\right)<0$ & Negative & Positive \\
$g_{3}\left(T_{1}\right) \leq 0$ and $g_{3}\left(T_{1}+M\right) \geq 0$ & Negative for $T_{A}^{3} \in\left[T_{1}, T_{g}^{3}\right]$ and positive for $T_{A}^{3} \in\left[T_{g}^{3}, T_{1}+M\right]$ & Positive \\
\hline
\end{tabular}

Note: $T_{g}^{3} \in\left[T_{1}, T_{1}+M\right]$ and satisfies $g_{3}\left(T_{g}^{3}\right)=0$, where $g_{3}\left(T_{A}^{3}\right)=p I_{e} e^{b T_{A}^{3}}\left(b T_{A}^{3}-1\right)\left(1-e^{-b M}\right)+c I_{k}\left[e^{b\left(T_{A}^{3}-M\right)}\left(b T_{A}^{3}-1\right)+1\right]$.

TABLE 6: The retailer's optimal ordering cycle for $T \in\left[T_{1}+M,+\infty\right]$.

\begin{tabular}{lcc}
\hline Situations & Conditions & Optimal solutions \\
\hline$c_{42}<0$ & $f_{4}\left(T_{1}+M\right) \geq 0$ & $T_{A}^{4}$ \\
& $f_{4}\left(T_{1}+M\right)<0$ & $T_{1}+M$ \\
\hline$c_{42}>0$ & $/$ & $+\infty$ \\
\hline \multirow{2}{*}{$c_{42}=0$} & $c_{43}>0$ & $T_{1}+M$ \\
& $c_{43}<0$ & $+\infty$ \\
& $c_{43}=0$ & Any value on $\left[T_{1}+M,+\infty\right)$ \\
\hline
\end{tabular}

Note: $T_{A}^{4} \in\left[T_{1}+M,+\infty\right)$ and satisfies $f_{4}\left(T_{A}^{4}\right)=0$.

and $c_{42}>c_{32}$. Consequently, by means of Lemmas 1-10 and multiple combinations of $\Delta_{3}, \Delta_{4}$, and $\Delta_{5}$, Theorem 12 can be obtained to determine the optimal cycle time $T^{*}$ for Case 2. For simplicity, we take the lower boundary of the time interval as $T^{*}$ when infinitely many optimal solutions exist.

Theorem 12. If $T_{1} \leq M \leq T_{1}+M$, the theoretical results in Table 10 can be obtained.

\section{Numerical Examples}

In this section, several numerical examples are provided to illustrate the theorems mentioned above. The sensitivity analyses of the major parameters will also be carried out to demonstrate the distinct advantages of the new policy.

Example 1. Given $A=430, a=300, b=0.80, p=28, c=23$, $h=8, I_{e}=0.06, I_{k}=0.08, M=0.20, Q_{1}=250$.

Consequently, we can find that $M<T_{1}=0.64, c_{22}=$ $-2600.41 \leq 0, c_{32}=-3462.91<0, c_{42}=-2727.94<0$, $\Delta_{1}=393.85>0, \Delta_{2}=-49.41 \leq 0$, and $\Delta_{3}=-643.21<0$. Thus according to Theorem 9, using (3) and (12), the optimal ordering cycle $T^{*}$, the optimal ordering quantity $Q^{*}$, and the optimal profit $\Pi\left(T^{*}\right)$ are $0.61,235.73$, and 301.95 , respectively.

Example 2. In this example, the retailer's optimal solutions under LOC clause and full delay payment are derived, respectively. And then the comparison between the two solutions is made for studying the influence of the given LOC clause on the retailer's ordering quantity. As the full delay payment policy is a special case of LOC payment scheme (i.e., setting $Q_{1}=+\infty$ ), the retailer's optimal ordering quantity under full delay payment can be figured out on the basis of Lemmas 1 and 3 (with proper transformations). For simplicity, we let $Q_{1}=250$ and $A p^{*}$ denote the account payable of the retailer under LOC clause. That is, if $Q^{*}>Q_{1}$, $A p^{*}$ equals $c Q_{1}$; otherwise, $A p^{*}$ would be $c Q^{*}$. Likewise, let
$Q^{\prime}$ and $A p^{\prime}$ denote the retailer's optimal ordering quantity and corresponding account payable under full delay payment policy, respectively; then we have $A p^{\prime}=c Q^{\prime}$. The values of other parameters remain the same as in Example 1 while inventory-level consumption rate $b$, selling price $p$, and credit period $M$ change independently. The results are summarized in Table 11.

From the data in Table 11, it can be seen that when the retailer's optimal ordering quantity under full delay payment $Q^{\prime}$ is less than the given value $Q_{1}$, both payment schemes derive the same optimal solutions, such as $b=0.60, p=28$, and $M=0.10$. That is, under the circumstance, LOC clause does not play a role in the constraint of retailer's ordering quantity. However, when $Q^{\prime}$ is greater than $Q_{1}$ (such as $b=$ $1.20, p=30$, and $M=0.60$ ), we can obtain completely different results as follows.

(1) When $Q^{\prime}$ is more than the given value $Q_{1}$, the results under LOC payment scheme are significantly less than those under full delay payment policy, especially for the retailer's account payable. Taking $b=1.20$ as an example, compared with $Q^{\prime}, Q^{*}$ reduces by $7.46 \%$. Correspondingly, $A p^{*}$ decreases sharply by $22.51 \%$ in contrast with $A p^{\prime}$. Furthermore, in this case, although LOC clause indeed can lower the retailer's ordering quantity, he/she may still place an order more than the given value $Q_{1}$ (e.g., $b=1.20, Q^{*}=298.56>Q_{1}=$ 250). This is because the increased selling profit offsets the additional costs. To conclude, by comparison with full delay payment policy, LOC payment scheme is verified to be effective in influencing the retailer's ordering quantity and restraining the retailer from excessive occupation of the supplier's cash flow.

(2) According to the data in Table 11, it is easy to find that, under both payment schemes, higher values of $b, p$, and $M$ result in higher values of $Q^{*}$ and $Q^{\prime}$. Consequently, for the given value $Q_{1}$, with the increase of the parameters, the retailer is more likely to place an increased order $Q^{*}$ exceeding $Q_{1}$. However, we can easily find that the account payable $A p^{*}$ can still keep constant as $c Q_{1}$ when $Q^{\prime}>Q_{1}$. For instance, when $b=0.60, Q^{*}=210.25$, which is less than $Q_{1}$. When $b=1.00, Q^{*}=264.76$, which gradually increases to be more than $Q_{1}$ with $A p^{*}$ reaching a stable value at 5750.00. Meanwhile, according to the changes of $\left(Q^{\prime}-\right.$ $\left.Q^{*}\right) / Q^{\prime}$ and $\left(A p^{\prime}-A p^{*}\right) / A p^{\prime}$, it can be seen that the restriction effect of LOC clause towards the retailer's ordering quantity and corresponding account payable would be more significant under higher values of $b, p$, 
TABLE 7: The relationships between the retailer's optimal ordering cycle $T_{A}^{4}$ and LOC clause.

\begin{tabular}{lcc}
\hline Situations & The relationship between $T_{A}^{4}$ and $M$ & The relationship between $T_{A}^{4}$ and $T_{1}$ \\
\hline$g_{4}\left(T_{1}+M\right)>0$ & Positive & Positive \\
$g_{4}\left(T_{1}+M\right) \leq 0$ & Negative for $T_{A}^{4} \in\left[T_{1}+M, T_{g}^{4}\right]$ and positive for $T_{A}^{4} \in\left[T_{g}^{4}, T_{1}+M\right]$ & Positive \\
\hline
\end{tabular}

Note: $T_{g}^{4} \in\left[T_{1}+M,+\infty\right)$ and satisfies $g_{4}\left(T_{g}^{4}\right)=0$, where $g_{4}\left(T_{A}^{4}\right)=p I_{e} e^{b T_{A}^{4}}\left(b T_{A}^{4}-1\right)\left(1-e^{-b M}\right)-c I_{k}\left(e^{b T_{1}}-1\right)$.

TABLE 8: The retailer's optimal ordering cycle for $M<T_{1} \leq T_{1}+M$.

\begin{tabular}{|c|c|c|c|}
\hline Situations & Conditions & $\Pi\left(T^{*}\right)$ & $T^{*}$ \\
\hline$c_{42}>0$ & l & $+\infty$ & $+\infty$ \\
\hline \multirow{7}{*}{$c_{22}>0$ and $c_{42} \leq 0$} & $\Delta_{1} \geq 0, \Delta_{2}>0, \Delta_{3}>0$, and $c_{42}=0$ & $+\infty$ & $+\infty$ \\
\hline & $\Delta_{1} \geq 0, \Delta_{2}>0, \Delta_{3}>0$, and $c_{42}<0$ & $\Pi_{4}\left(T_{A}^{4}\right)$ & $T_{A}^{4}$ \\
\hline & $\Delta_{1} \geq 0, \Delta_{2}>0$, and $\Delta_{3} \leq 0$ & $\Pi_{3}\left(T_{A}^{3}\right)$ & $T_{A}^{3}$ \\
\hline & $\Delta_{1}<0, \Delta_{2}>0, \Delta_{3}>0$, and $c_{42}=0$ & $+\infty$ & $+\infty$ \\
\hline & $\Delta_{1}<0, \Delta_{2}>0, \Delta_{3}>0$, and $c_{42}<0$ & $\max \left\{\Pi_{1}\left(T_{A}^{1}\right), \Pi_{4}\left(T_{A}^{4}\right)\right\}$ & $T_{A}^{1}$ or $T_{A}^{4}$ \\
\hline & $\Delta_{1}<0, \Delta_{2}>0$, and $\Delta_{3} \leq 0$ & $\max \left\{\Pi_{1}\left(T_{A}^{1}\right), \Pi_{3}\left(T_{A}^{3}\right)\right\}$ & $T_{A}^{1}$ or $T_{A}^{3}$ \\
\hline & $\Delta_{1}<0, \Delta_{2} \leq 0$, and $\Delta_{3}<0$ & $\Pi_{1}\left(T_{A}^{1}\right)$ & $T_{A}^{1}$ \\
\hline \multirow{4}{*}{$c_{22} \leq 0$ and $c_{42}<0$} & $\Delta_{1}>0, \Delta_{2}>0$, and $\Delta_{3}>0$ & $\Pi_{4}\left(T_{A}^{4}\right)$ & $T_{A}^{4}$ \\
\hline & $\Delta_{1}>0, \Delta_{2}>0$, and $\Delta_{3} \leq 0$ & $\Pi_{3}\left(T_{A}^{3}\right)$ & $T_{A}^{3}$ \\
\hline & $\Delta_{1}>0, \Delta_{2} \leq 0$, and $\Delta_{3}<0$ & $\Pi_{2}\left(T_{A}^{2}\right)$ & $T_{A}^{2}$ \\
\hline & $\Delta_{1} \leq 0, \Delta_{2} \leq 0$, and $\Delta_{3}<0$ & $\Pi_{1}\left(T_{A}^{1}\right)$ & $T_{A}^{1}$ \\
\hline
\end{tabular}

TABLE 9: The retailer's optimal ordering cycle for $T \in\left[T_{1}, M\right]$.

\begin{tabular}{lcc}
\hline Situations & Conditions & Optimal solutions \\
\hline \multirow{3}{*}{$c_{52}<0$} & $f_{5}(M)>0$ & $M$ \\
& $f_{5}\left(T_{1}\right)<0$ & $T_{1}$ \\
& $f_{5}\left(T_{1}\right) \geq 0$ and $f_{5}(M) \leq 0$ & $T_{A}^{5}$ \\
\hline \multirow{3}{*}{$c_{52}>0$} & $f_{5}\left(T_{1}\right)>0$ & $M$ \\
& $f_{5}(M)<0$ & $T_{1}$ \\
& $f_{5}(M) \geq 0$ and $f_{5}\left(T_{1}\right) \leq 0$ & $T_{1}$ or $M$ \\
\hline \multirow{2}{*}{$c_{52}=0$} & $c_{53}>0$ & $T_{1}$ \\
& $c_{53}<0$ & $M$ \\
& $c_{53}=0$ & Any value on $\left[T_{1}, M\right]$ \\
\hline
\end{tabular}

Note: $T_{A}^{5} \in\left[T_{1}, M\right]$ and satisfies $f_{5}\left(T_{A}^{5}\right)=0$.

TABLE 10: The retailer's optimal ordering cycle for $T_{1} \leq M \leq T_{1}+M$.

\begin{tabular}{lccc}
\hline Situations & Conditions & $\Pi\left(T^{*}\right)$ & $T^{*}$ \\
\hline$c_{42}>0$ & $/$ & $+\infty$ & $+\infty$ \\
\hline & $\Delta_{4}>0, \Delta_{5}>0, \Delta_{3}>0$, and $c_{42}=0$ & $+\infty$ & $+\infty$ \\
& $\Delta_{4}>0, \Delta_{5}>0, \Delta_{3}>0$, and $c_{42}<0$ & $\Pi_{4}\left(T_{A}^{4}\right)$ & $T_{A}^{4}$ \\
$c_{42} \leq 0$ & $\Delta_{4}>0, \Delta_{5}>0$, and $\Delta_{3} \leq 0$ & $\Pi_{3}\left(T_{A}^{3}\right)$ & $T_{A}^{3}$ \\
& $\Delta_{4}>0, \Delta_{5} \leq 0$, and $\Delta_{3}<0$ & $\Pi_{5}\left(T_{A}^{5}\right)$ & $T_{A}^{5}$ \\
& $\Delta_{4} \leq 0, \Delta_{5}<0$, and $\Delta_{3}<0$ & $\Pi_{1}\left(T_{A}^{1}\right)$ & $T_{A}^{1}$ \\
\hline
\end{tabular}

and $M$, and thus a reasonable account payable can be maintained.

Example 3. This example still takes the perspective of retailer to obtain the optimal ordering quantity $Q^{*}$ under LOC clause, but a new criterion is employed to evaluate the retailer's decision. The purpose of the example is to propose the new possible incentives for the retailer's excessive ordering quantity and demonstrate how to formulate an appropriate LOC clause (i.e., change the value of $Q_{1}$ ) to successively approximate $Q^{*}$ to that new criterion. More details and results are presented as follows.

According to Wang and Gerchak [28], the competition between the retailers accounts for the higher amount of inventory in the distribution channel. Following the analysis procedure of Wang and Gerchak [28], we consider a decisionmaking scenario in the context of decentralized supply chain below.

Firstly, we assume that the supplier takes charge of the selling of the item (i.e., setting $M=0$ and $Q_{1}=+\infty$ ) to figure out his/her desired ordering quantity $Q^{d}$. Let the supplier's purchase price $c_{s}=21$ and the rate of capital opportunity cost of the supplier equals 0.16 (to calculate the stock holding cost) while the values of other parameters keep the same as in Example 1. Hence, based on Lemma 3 (with proper transformations), the supplier's desired ordering quantity $Q^{d}$ turns out to be 230.73, which is served as the benchmark of the ordering quantity in the channel.

Next, we consider a decentralized system where the supplier, through the LOC clause, wholesales the product to the retailer, who then sells the item to the customers. Our goal is to determine the retailer's optimal ordering quantity $Q^{*}$ under LOC clause for the given wholesale price $c$ (i.e., the formulated model based on LOC clause), and the values of parameters are the same as in Example 1. Under the circumstance, as $c>c_{s}, Q^{*}$ may be less than $Q^{d}$, which is known as double marginalization of the decentralized supply chain. However, in the context of delay in payments, a longer credit period $M$ offered by the supplier and a lower value of $I_{k}$ may stimulate the retailer to order more quantity exceeding 
TABLE 11: The comparisons of the retailer's optimal solutions between full delay payment and LOC payment scheme with different values of $b, p$, and $M$.

\begin{tabular}{|c|c|c|c|c|c|c|c|}
\hline & \multirow[t]{2}{*}{ Parameters } & \multicolumn{2}{|c|}{$\begin{array}{l}\text { Optimal solutions under full delay } \\
\text { payment }\end{array}$} & \multicolumn{2}{|c|}{ Optimal solutions under LOC } & \multirow{2}{*}{$\frac{Q^{\prime}-Q^{*}}{Q^{\prime}}$} & \multirow{2}{*}{$\frac{A p^{\prime}-A p^{*}}{A p^{\prime}}$} \\
\hline & & $Q^{\prime}$ & $A p^{\prime}$ & $Q^{*}$ & $A p^{*}$ & & \\
\hline \multirow{6}{*}{$b$} & 0.40 & 190.65 & 4384.95 & 190.65 & 4384.99 & $0.00 \%$ & $0.00 \%$ \\
\hline & 0.60 & 210.25 & 4835.75 & 210.25 & 4835.80 & $0.00 \%$ & $0.00 \%$ \\
\hline & 0.80 & 235.73 & 5421.79 & 235.73 & 5421.79 & $0.00 \%$ & $0.00 \%$ \\
\hline & 1.00 & 270.67 & 6225.41 & 264.76 & 5750.00 & $2.18 \%$ & $7.64 \%$ \\
\hline & 1.20 & 322.64 & 7420.72 & 298.56 & 5750.00 & $7.46 \%$ & $22.51 \%$ \\
\hline & 1.40 & 411.21 & 9457.83 & 346.22 & 5750.00 & $15.80 \%$ & $39.20 \%$ \\
\hline \multirow{6}{*}{$p$} & 28 & 235.73 & 5421.79 & 235.73 & 5043.67 & $0.00 \%$ & $0.00 \%$ \\
\hline & 29 & 256.40 & 5897.20 & 254.62 & 5750.00 & $0.69 \%$ & $2.49 \%$ \\
\hline & 30 & 283.43 & 6518.89 & 273.14 & 5750.00 & $3.63 \%$ & $11.79 \%$ \\
\hline & 31 & 320.86 & 7379.78 & 296.23 & 5750.00 & $7.68 \%$ & $22.09 \%$ \\
\hline & 32 & 377.45 & 8681.35 & 326.07 & 5750.00 & $13.61 \%$ & $33.77 \%$ \\
\hline & 33 & 477.24 & 10976.52 & 373.67 & 5750.00 & $21.70 \%$ & $47.62 \%$ \\
\hline \multirow{6}{*}{$M$} & 0.05 & 230.61 & 5304.03 & 230.61 & 5303.92 & $0.00 \%$ & $0.00 \%$ \\
\hline & 0.10 & 232.25 & 5341.75 & 232.25 & 5341.82 & $0.00 \%$ & $0.00 \%$ \\
\hline & 0.20 & 235.73 & 5421.79 & 235.73 & 5421.79 & $0.00 \%$ & $0.00 \%$ \\
\hline & 0.40 & 243.43 & 5598.89 & 243.43 & 5598.84 & $0.00 \%$ & $0.00 \%$ \\
\hline & 0.60 & 252.16 & 5799.68 & 251.57 & 5750.00 & $0.23 \%$ & $0.86 \%$ \\
\hline & 0.80 & 260.48 & 5991.04 & 257.52 & 5750.00 & $1.14 \%$ & $4.02 \%$ \\
\hline
\end{tabular}

$Q^{d}$. This phenomenon can be observed from the first line in Tables 12 and 13, that is, the retailer's ordering quantity under full delay payment policy with a specific value of $I_{k}$ or $M$.

Finally, in order to formulate an appropriate LOC clause, the value of $Q_{1}$ is continuously changed until the value of $Q^{*}$ becomes close enough to $Q^{d}$. In Table 12, for different values of $I_{k}$, we alter the value of $Q_{1}$ to approximate $Q^{*}$ to $Q^{d}$. And for different values of $M$, we apply the same operations to obtain the results shown in Table 13.

Based on the data in Table 12, it can be observed that, under full delay payment policy (i.e., $Q_{1}=+\infty$ ), the retailer orders more quantity than $Q^{d}$ since $I_{k}$ shown in Table 12 is relatively lower than that of the supplier (which equals 0.16). Accordingly, with the employment of LOC clause, the supplier is able to manipulate the value of $Q_{1}$ to approximate $Q^{*}$ to $Q^{d}$. Taking $I_{k}=0.70$ as an example, due to the employment of LOC clause with $Q_{1}=190, Q^{*}$ drops from 239.97 to 229.19 , which is quite close to $Q^{d}=230.73$.

From the data in Table 13, it can be found that under full delay payment policy (i.e., $Q_{1}=+\infty$ ), for $M=0.10$, the optimal ordering quantity of retailer $Q^{*}$ is 232.25 , which is close to $Q^{d}=230.73$. However, as $M=0.40$, the difference between $Q^{*}$ and $Q^{d}$ increases; that is, a longer credit period $M$ may stimulate the retailer to order excessive quantity more than $Q^{d}$. Accordingly, for the given value $M$, by decreasing the value of $Q_{1}$, the retailer would choose the optimal ordering quantity $Q^{*}$ close to $Q^{d}$ voluntarily. For instance, as $M=0.4$, the value of $Q_{1}$ could be lowered to 190 to approximate $Q^{*}$ (which equals 230.54) to $Q^{d}$.
TABLE 12: The impact of the change of $Q_{1}$ on the optimal policies with different $I_{k}$.

\begin{tabular}{ccccc}
\hline \multicolumn{2}{c}{ Parameters } & $I_{k}=0.07$ & $I_{k}=0.08$ & $I_{k}=0.09$ \\
& & $Q^{*}$ & $Q^{*}$ & $Q^{*}$ \\
\hline \multirow{4}{*}{$Q_{1}$} & $+\infty$ & 239.97 & 235.73 & 231.73 \\
& 250 & 239.97 & 235.73 & 231.73 \\
& 230 & 237.69 & 234.31 & 231.27 \\
& 210 & 233.31 & 229.54 & 226.14 \\
& 190 & 229.19 & 225.04 & 221.30 \\
& 170 & 225.37 & 220.86 & 216.78 \\
\hline
\end{tabular}

TABLE 13: The impact of the change of $Q_{1}$ on the optimal policies with different $M$.

\begin{tabular}{|c|c|c|c|c|}
\hline \multicolumn{2}{|c|}{ Parameters } & $M=0.10$ & $M=0.20$ & $\begin{array}{c}M=0.40 \\
O^{*}\end{array}$ \\
\hline \multirow{6}{*}{$Q_{1}$} & $+\infty$ & 232.25 & 235.73 & 243.43 \\
\hline & 250 & 232.25 & 235.73 & 243.43 \\
\hline & 230 & 231.70 & 234.31 & 240.00 \\
\hline & 210 & 226.98 & 229.54 & 235.13 \\
\hline & 190 & 222.53 & 225.04 & 230.54 \\
\hline & 170 & 219.26 & 220.86 & 226.27 \\
\hline
\end{tabular}

To sum up, a lower value of $I_{k}$ or a higher value of $M$ may stimulate the retailer to order excessively, which differs from the conclusion from previous research. And from Tables 12 and 13, it can be seen that an appropriate value of $Q_{1}$ is 
essential to control the retailer's ordering quantity even to approximate $Q^{*}$ to the desired ordering quantity $Q^{d}$.

\section{Conclusion}

Practically, granting a longer credit period to the retailer not only induces a higher default risk but also intensifies the supplier's cash-flow pressure, especially when demand rate of the item is dependent upon inventory level. Therefore, the LOC payment scheme can be employed to influence the retailer's ordering policy in the supply chain. To supplement the study of this widely adopted policy, in this paper we develop an EOQ model with the inventory-level-dependent demand under the two-parameter LOC clause. Based on relationships among parameters, two cases as well as corresponding profit functions of the retailer are considered in the model. Furthermore, five lemmas and two easy-to-use theorems are established to identify the optimal ordering policy of the retailer. Based on the above numerical examples, some managerial insights are presented as follows.

(1) Besides the competition between the retailers, under the circumstance of credit-period-only policy a longer credit period $M$ and a lower rate of capital opportunity cost of the retailer $I_{k}$ may also cause the retailer to order excessively.

(2) In practice, the two-parameter LOC clause could be applied to induce the retailer to place an appropriate ordering quantity and maintain a reasonable account payable.

(3) The two-parameter LOC clause explicitly defines the upper limit of the retailer's account payable, thus preventing the supplier from falling into the dilemma mentioned before in the physical distribution channel (i.e., higher sales volume accompanied by higher cash-flow pressure).

It should be mentioned that when considering the item with constant demand rate, that is, setting $b=0$ in our model, the same conclusions can be obtained in the context of LOC clause. And the proposed LOC clause could be extended to the following research directions.

(1) An interesting phenomenon will arise when extending the model to the multi-item scenario. Since every item has different demand rate or selling price, the retailer should allocate LOC share among different items to determine his/her optimal replenishment policy.

(2) Taking temporary price reduction into account, credit period would play the role as inventory-subsidy for the retailer's special order in the period of trade promotion while the accompanied LOC clause could be used to measure the retailer's account payable.

(3) Practically, the supplier could grant the retailer either early payment discount or LOC clause to ensure his/her account receivable. Thus the retailer may weigh the advantages and disadvantages of both payment schemes to determine the optimal selection of trade credit and corresponding ordering policy.

\section{Appendix}

\section{A. Proof of Lemma 1}

To prove Lemma 1, we should discuss various situations based on the value of $c_{12}$. And it should be noted that $f_{1}(0)=A>0$.

(1) When $c_{12}<0, \mathrm{~d} f_{1}(T) / \mathrm{d} T<0$. That is, $f_{1}(T)$ is decreasing in $[0, M]$.

(i) If $f_{1}(M)>0$, we have $f_{1}(T)>0$ for all $T \in[0, M]$ and $\mathrm{d}_{1}(T) / \mathrm{d} T=f_{1}(T) / T^{2} \geq 0$. Hence, $\Pi_{1}(T)$ is increasing in $[0, M]$ and has a maximum value at the upper boundary point $T=M$.

(ii) If $f_{1}(M) \leq 0$, there exists a unique solution (e.g., $T_{A}^{1}$ ) over $[0, M]$ satisfying the equation of $f_{1}(T)=0$ by applying Intermediate Value Theorem. As $\left.\left(\mathrm{d}^{2} \Pi_{1}(T) / \mathrm{d} T^{2}\right)\right|_{T=T_{A}^{1}}=a c_{12} T_{A}^{1} e^{b T_{A}^{1}}<0$, $T_{A}^{1} \in(0, M]$ is the unique maximum solution to $\Pi_{1}(T)$.

(2) When $c_{12} \geq 0$, we have that $f_{1}(T)$ is a nondecreasing function in $[0, M]$. And since $f_{1}(0)=A$, we know that $f_{1}(T)>0$. Thus, $\mathrm{d} \Pi_{1}(T) / \mathrm{d} T>0$ and $\Pi_{1}(T)$ is strictly increasing in $[0, M]$ and has a maximum value at the upper boundary point $T=M$.

This completes the proof of Appendix A.

\section{B. Proof of Corollary 2}

To prove Corollary 2, taking the first-order derivative of the expression $f_{1}\left(T_{A}^{1}\right)=0$ with respect to $M$, we can have

$$
\frac{a p I_{e} g_{1}\left(T_{A}^{1}\right)}{b}+a c_{12} T_{A}^{1}(M) e^{b T_{A}^{1}(M)} \frac{\mathrm{d} T_{A}^{1}(M)}{\mathrm{d} M}=0,
$$

where

$$
g_{1}\left(T_{A}^{1}\right)=b T_{A}^{1} e^{b T_{A}^{1}}-e^{b T_{A}^{1}}+1 .
$$

By taking the first-order derivative of $g_{1}\left(T_{A}^{1}\right)$ with respect to $T_{A}^{1}$, we can find that $\mathrm{d} g_{1}\left(T_{A}^{1}\right) / \mathrm{d} T=T_{A}^{1} b^{2} e^{b T_{A}^{1}} \geq 0$ and $g_{1}(0)=0$, and thus $g_{1}\left(T_{A}^{1}\right) \geq 0$ for $T_{A}^{1} \in[0, M]$.

Considering that $c_{12}<0$, we have $\mathrm{d} T_{A}^{1}(M) / \mathrm{d} M>0$. That is, the value of $T_{A}^{1}$ is positively associated with the credit period $M$.

This completes the proof of Appendix B.

\section{Proof of Lemma 3}

To prove Lemma 3, we should discuss various situations based on the value of $c_{22}$. 
(1) When $c_{22}<0$, we have $\mathrm{d} f_{2}(T) / \mathrm{d} T<0$. That is, $f_{2}(T)$ is decreasing on $\left[M, T_{1}\right]$.

(i) If $f_{2}\left(T_{1}\right)>0$, we have $f_{2}(T)>0$ for all $T \in\left[M, T_{1}\right]$ and $\mathrm{d}_{2}(T) / \mathrm{d} T=f_{2}(T) / T^{2} \geq 0$. Hence, $\Pi_{2}(T)$ is increasing in $\left[M, T_{1}\right]$ and has a maximum value at the upper boundary point $T=T_{1}$.

(ii) If $f_{2}(M)<0$, we have $f_{2}(T)<0$ for all $T \in\left[M, T_{1}\right]$ and $\mathrm{d}_{2}(T) / \mathrm{d} T=f_{2}(T) / T^{2} \leq 0$. Hence, $\Pi_{2}(T)$ is decreasing in $\left[M, T_{1}\right]$ and has a maximum value at the lower boundary point $T=M$

(iii) If $f_{2}(M) \geq 0$ and $f_{2}\left(T_{1}\right) \leq 0$, there exists a unique solution (e.g., $T_{A}^{2}$ ) over $\left[M, T_{1}\right]$ satisfying the equation of $f_{2}(T)=0$ by applying Intermediate Value Theorem. As $\left.\left(\mathrm{d}^{2} \Pi_{2}(T) / \mathrm{d} T^{2}\right)\right|_{T=T_{A}^{2}}=$ $a c_{22} T_{A}^{2} e^{b T_{A}^{2}}<0, T_{A}^{2} \in\left[M, T_{1}\right]$ is the unique maximum solution to $\Pi_{2}(T)$.

(2) When $c_{22}>0$, we have $\mathrm{d} f_{2}(T) / \mathrm{d} T>0$. That is, $f_{2}(T)$ is increasing on $\left[M, T_{1}\right]$.

(i) If $f_{2}(M)>0$, we have $f_{2}(T)>0$ for all $T \in\left[M, T_{1}\right]$ and $\mathrm{d}_{2}(T) / \mathrm{d} T=f_{2}(T) / T^{2} \geq 0$. Hence, $\Pi_{2}(T)$ is increasing in $\left[M, T_{1}\right]$ and has a maximum value at the upper boundary point $T=T_{1}$.

(ii) If $f_{2}\left(T_{1}\right)<0$, we have $f_{2}(T)<0$ for all $T \in\left[M, T_{1}\right]$ and $\mathrm{d} \Pi_{2}(T) / \mathrm{d} T=f_{2}(T) / T^{2} \leq 0$. Hence, $\Pi_{2}(T)$ is decreasing in $\left[M, T_{1}\right]$ and has a maximum value at the lower boundary point $T=M$.

(iii) If $f_{2}(M) \leq 0$ and $f_{2}\left(T_{1}\right) \geq 0$, there exists a unique solution (e.g., $T_{B}^{2}$ ) over $\left[M, T_{1}\right]$ satisfying the equation of $f_{2}(T)=0$ by applying Intermediate Value Theorem. Since $\left.\left(\mathrm{d}^{2} \Pi_{2}(T) / \mathrm{d} T^{2}\right)\right|_{T=T_{B}^{2}}=a c_{22} T_{B}^{2} e^{b T_{B}^{2}}>0, T_{B}^{2}$ is the minimum value point in the feasible region. Hence, $T=M$ or $T=T_{1}$ is the maximum solution to $\Pi_{2}(T)$.

(3) When $c_{22}=0$, we have $\mathrm{d} \Pi_{2}(T) / \mathrm{d} T=f_{2}(T) / T^{2}=$ $-c_{23} / T^{2}$.

(i) If $c_{23}>0$, we have that $\Pi_{2}(T)$ is decreasing in $\left[M, T_{1}\right]$ and has a maximum value at the lower boundary point $T=M$.

(ii) If $c_{23}<0$, we have that $\Pi_{2}(T)$ is increasing in $\left[M, T_{1}\right]$ and has a maximum value at the upper boundary point $T=T_{1}$.

(iii) If $c_{23}=0$, we have that $\Pi_{2}(T)$ is constant in $\left[M, T_{1}\right]$.

This completes the proof of Appendix C.

\section{Proof of Corollary 4}

To prove Corollary 4, taking the first-order derivative of the expression $f_{2}\left(T_{A}^{2}\right)=0$ with respect to $M$, we can have

$$
\frac{a}{b} g_{2}\left(T_{A}^{2}\right)+a c_{22} T_{A}^{2}(M) e^{b T_{A}^{2}(M)} \frac{\mathrm{d} T_{A}^{2}(M)}{\mathrm{d} M}=0,
$$

where

$$
\begin{aligned}
g_{2}\left(T_{A}^{2}\right)= & p I_{e} e^{b T_{A}^{2}}\left(b T_{A}^{2}-1\right)\left(1-e^{-b M}\right) \\
& +c I_{k}\left[e^{b\left(T_{A}^{2}-M\right)}\left(b T_{A}^{2}-1\right)+1\right] .
\end{aligned}
$$

By taking the first-order derivative of $g_{2}\left(T_{A}^{2}\right)$ with respect to $T_{A}^{2}$, we can find that $\mathrm{d} g_{2}\left(T_{A}^{2}\right) / \mathrm{d} T=b^{2} T_{A}^{2} e^{b\left(T_{A}^{2}-M\right)}\left[p I_{e}\left(e^{b M}-\right.\right.$ $\left.1)+c I_{k}\right]>0$. That is, $g_{2}\left(T_{A}^{2}\right)$ is increasing on $\left[M, T_{1}\right]$.

Considering that $c_{22}<0$, there are three subcases to be further classified.

(1) If $g_{2}(M)>0$, we have $g_{2}\left(T_{A}^{2}\right)>0$ for all $T_{A}^{2} \in\left[M, T_{1}\right]$ and we have $\mathrm{d} T_{A}^{2}(M) / \mathrm{d} M>0$. That is, the value of $T_{A}^{2}$ is positively associated with the credit period $M$.

(2) If $g_{2}\left(T_{1}\right)<0$, we have $g_{2}\left(T_{A}^{2}\right)<0$ for all $T_{A}^{2} \in\left[M, T_{1}\right]$ and we have $\mathrm{d} T_{A}^{2}(M) / \mathrm{d} M<0$. That is, the value of $T_{A}^{2}$ is negatively associated with the credit period $M$.

(3) If $g_{2}(M) \leq 0$ and $g_{2}\left(T_{1}\right) \geq 0$, there exists a unique solution (e.g., $T_{g}^{2}$ ) over $\left[M, T_{1}\right]$ satisfying the equation of $g_{2}\left(T_{g}^{2}\right)=0$ by applying Intermediate Value Theorem. Thus, we have $\mathrm{d} T_{A}^{2}(M) / \mathrm{d} M \leq 0$ for all $T_{A}^{2} \in\left[M, T_{g}^{2}\right]$ and $\mathrm{d} T_{A}^{2}(M) / \mathrm{d} M \geq 0$ for all $T_{A}^{2} \in\left[T_{g}^{2}, T_{1}\right]$. That is, the value of $T_{A}^{2}$ is negatively associated with the credit period $M$ within $T_{A}^{2} \in$ $\left[M, T_{g}^{2}\right]$ and is positively associated with the credit period $M$ during $T_{A}^{2} \in\left[T_{g}^{2}, T_{1}\right]$.

This completes the proof of Appendix D.

\section{Competing Interests}

The authors declare that there are no competing interests regarding the publication of this paper.

\section{Acknowledgments}

The research presented in this paper is supported by the National Natural Science Foundation Project of China (71271168, 70871097).

\section{References}

[1] N. Wilson and B. Summers, "Trade credit terms offered by small firms: survey evidence and empirical analysis," Journal of Business Finance and Accounting, vol. 29, no. 3-4, pp. 317-351, 2002.

[2] S. K. Goyal, "Economic order quantity under conditions of permissible delay in payments," Journal of the Operational Research Society, vol. 36, no. 4, pp. 335-338, 1985. 
[3] B. C. Giri and T. Maiti, "Supply chain model with priceand trade credit-sensitive demand under two-level permissible delay in payments," International Journal of Systems Science, vol. 44, no. 5, pp. 937-948, 2013.

[4] J.-T. Teng, K.-R. Lou, and L. Wang, "Optimal trade credit and lot size policies in economic production quantity models with learning curve production costs," International Journal of Production Economics, vol. 155, pp. 318-323, 2014.

[5] A. M. M. Jamal, B. R. Sarker, and S. Wang, "An ordering policy for deteriorating items with allowable shortage and permissible delay in payment," Journal of the Operational Research Society, vol. 48, no. 8, pp. 826-833, 1997.

[6] L.-Y. Ouyang, K.-S. Wu, and C.-T. Yang, "A study on an inventory model for non-instantaneous deteriorating items with permissible delay in payments," Computers and Industrial Engineering, vol. 51, no. 4, pp. 637-651, 2006.

[7] K. V. Geetha and R. Uthayakumar, "Economic design of an inventory policy for non-instantaneous deteriorating items under permissible delay in payments," Journal of Computational and Applied Mathematics, vol. 233, no. 10, pp. 2492-2505, 2010.

[8] J.-J. Liao, K.-J. Chung, and K.-N. Huang, "A deterministic inventory model for deteriorating items with two warehouses and trade credit in a supply chain system," International Journal of Production Economics, vol. 146, no. 2, pp. 557-565, 2013.

[9] B. Pal, S. S. Sana, and K. Chaudhuri, "Three stage trade credit policy in a three-layer supply chain-a production-inventory model," International Journal of Systems Science, vol. 45, no. 9, pp. 1844-1868, 2014.

[10] Z. Molamohamadi, R. Arshizadeh, and N. Ismail, "An EPQ inventory model with allowable shortages for deteriorating items under trade credit policy," Discrete Dynamics in Nature and Society, vol. 2014, Article ID 476085, 10 pages, 2014.

[11] K.-J. Chung, S. K. Goyal, and Y.-F. Huang, “The optimal inventory policies under permissible delay in payments depending on the ordering quantity," International Journal of Production Economics, vol. 95, no. 2, pp. 203-213, 2005.

[12] H.-C. Chang, C.-H. Ho, L.-Y. Ouyang, and C.-H. Su, "The optimal pricing and ordering policy for an integrated inventory model when trade credit linked to order quantity," Applied Mathematical Modelling, vol. 33, no. 7, pp. 2978-2991, 2009.

[13] V. B. Kreng and S.-J. Tan, “The optimal replenishment decisions under two levels of trade credit policy depending on the order quantity," Expert Systems with Applications, vol. 37, no. 7, pp. 5514-5522, 2010.

[14] Y. Liang and F. Zhou, "A two-warehouse inventory model for deteriorating items under conditionally permissible delay in payment," Applied Mathematical Modelling, vol. 35, no. 5, pp. 2221-2231, 2011.

[15] J. Wu, L.-Y. Ouyang, L. E. Cardenas-Barron, and S. K. Goyal, "Optimal credit period and lot size for deteriorating items with expiration dates under two-level trade credit financing," European Journal of Operational Research, vol. 237, no. 3, pp. 898-908, 2014.

[16] N. H. Shah and L. E. Cardenas-Barron, "Retailer's decision for ordering and credit policies for deteriorating items when a supplier offers order-linked credit period or cash discount," Applied Mathematics and Computation, vol. 259, pp. 569-578, 2015.

[17] Y.-F. Huang, "Economic order quantity under conditionally permissible delay in payments," European Journal of Operational Research, vol. 176, no. 2, pp. 911-924, 2007.
[18] L.-Y. Ouyang, J.-T. Teng, S. K. Goyal, and C.-T. Yang, "An economic order quantity model for deteriorating items with partially permissible delay in payments linked to order quantity," European Journal of Operational Research, vol. 194, no. 2, pp. 418-431, 2009.

[19] L.-Y. Ouyang, C.-T. Chang, and P. Shum, "The EOQ with defective items and partially permissible delay in payments linked to order quantity derived algebraically," Central European Journal of Operations Research (CEJOR), vol. 20, no. 1, pp. 141160, 2012.

[20] S.-C. Chen, J.-T. Teng, and K. Skouri, "Economic production quantity models for deteriorating items with up-stream full trade credit and down-stream partial trade credit," International Journal of Production Economics, vol. 155, pp. 302-309, 2014.

[21] J. Wu, F. B. Al-Khateeb, J.-T. Teng, and L. E. Cárdenas-Barrón, "Inventory models for deteriorating items with maximum lifetime under downstream partial trade credits to creditrisk customers by discounted cash-flow analysis," International Journal of Production Economics, vol. 171, pp. 105-115, 2016.

[22] K.-R. Lou and W.-C. Wang, "Optimal trade credit and order quantity when trade credit impacts on both demand rate and default risk," Journal of the Operational Research Society, vol. 64, no. 10, pp. 1551-1556, 2013.

[23] M. A. Petersen and R. G. Rajan, "Trade credit: theories and evidence," Review of Financial Studies, vol. 10, no. 3, pp. 661-691, 1997.

[24] G. Cai, X. Chen, and Z. Xiao, "The roles of bank and trade credits: theoretical analysis and empirical evidence," Production and Operations Management, vol. 23, no. 4, pp. 583-598, 2014.

[25] M. Burkart and T. Ellingsen, "In-kind finance: a theory of trade credit," American Economic Review, vol. 94, no. 3, pp. 569-590, 2004.

[26] T. L. Urban, "Inventory models with inventory-level-dependent demand: a comprehensive review and unifying theory," European Journal of Operational Research, vol. 162, no. 3, pp. 792804, 2005.

[27] R. C. Baker and T. L. Urban, "A deterministic inventory system with an inventory-level-dependent demand rate," Journal of the Operational Research Society, vol. 39, no. 9, pp. 823-831, 1988.

[28] Y. Wang and Y. Gerchak, "Supply chain coordination when demand is shelf-space dependent," Manufacturing \& Service Operations Management, vol. 3, no. 1, pp. 82-87, 2001.

[29] A. Balakrishnan, M. S. Pangburn, and E. Stavrulaki, “'Stack them high, let'em fly': lot-sizing policies when inventories stimulate demand," Management Science, vol. 50, no. 5, pp. 630644, 2004.

[30] K.-S. Wu, L.-Y. Ouyang, and C.-T. Yang, "An optimal replenishment policy for non-instantaneous deteriorating items with stock-dependent demand and partial backlogging," International Journal of Production Economics, vol. 101, no. 2, pp. 369384, 2006.

[31] C.-T. Chang, J.-T. Teng, and S. K. Goyal, “Optimal replenishment policies for non-instantaneous deteriorating items with stock-dependent demand," International Journal of Production Economics, vol. 123, no. 1, pp. 62-68, 2010.

[32] Y. Ghiami, T. Williams, and Y. Wu, "A two-echelon inventory model for a deteriorating item with stock-dependent demand, partial backlogging and capacity constraints," European Journal of Operational Research, vol. 231, no. 3, pp. 587-597, 2013.

[33] H. N. Soni, "Optimal replenishment policies for noninstantaneous deteriorating items with price and stock sensitive 
demand under permissible delay in payment," International Journal of Production Economics, vol. 146, no. 1, pp. 259-268, 2013.

[34] H.-C. Liao, C.-H. Tsai, and C.-T. Su, "Inventory model with deteriorating items under inflation when a delay in payment is permissible," International Journal of Production Economics, vol. 63, no. 2, pp. 207-214, 2000.

[35] J. Min, Y.-W. Zhou, and J. Zhao, "An inventory model for deteriorating items under stock-dependent demand and twolevel trade credit," Applied Mathematical Modelling, vol. 34, no. 11, pp. 3273-3285, 2010.

[36] J. Min, Y.-W. Zhou, G.-Q. Liu, and S.-D. Wang, "An EPQ model for deteriorating items with inventory-level-dependent demand and permissible delay in payments," International Journal of Systems Science, vol. 43, no. 6, pp. 1039-1053, 2012.

[37] L. E. Cárdenas-Barrón, K.-J. Chung, and G. Treviño-Garza, "Celebrating a century of the economic order quantity model in honor of Ford Whitman Harris," International Journal of Production Economics, vol. 155, pp. 1-7, 2014.

[38] J. Mo, G. Chen, T. Fan, and H. Mao, "Optimal ordering policies for perishable multi-item under stock-dependent demand and two-level trade credit," Applied Mathematical Modelling, vol. 38, no. 9, pp. 2522-2532, 2014. 


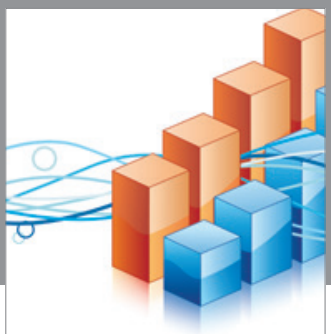

Advances in

Operations Research

vatem alat4

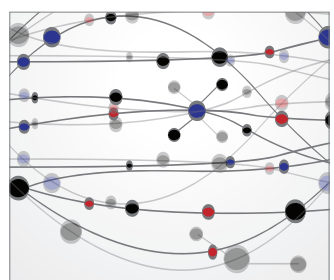

\section{The Scientific} World Journal
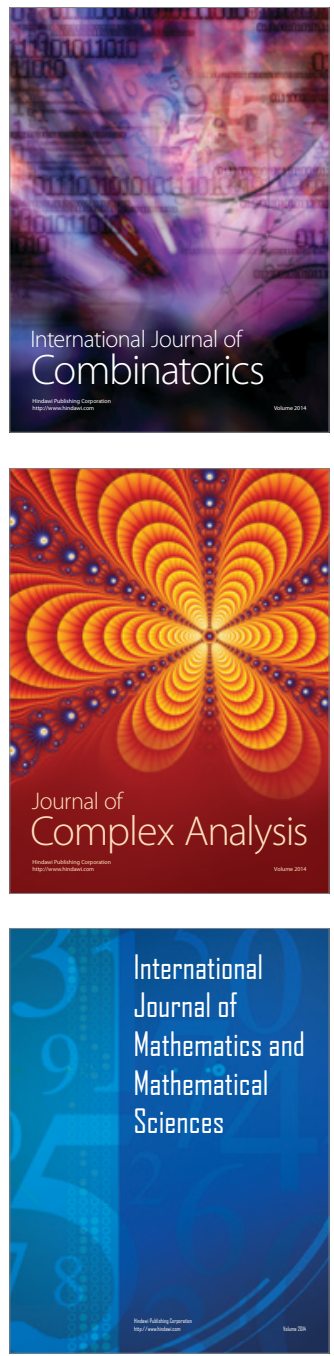
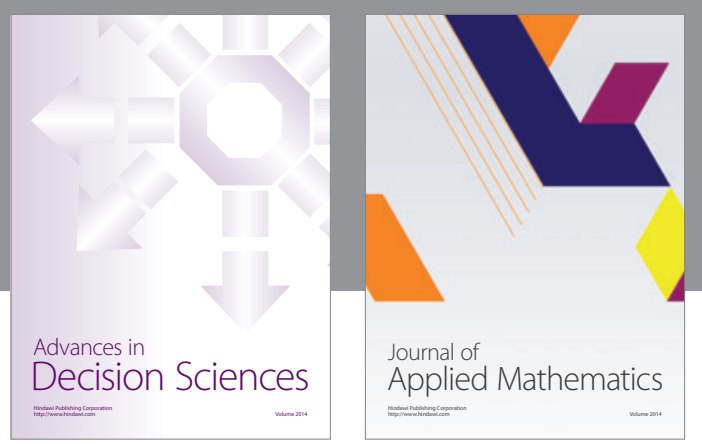

Algebra

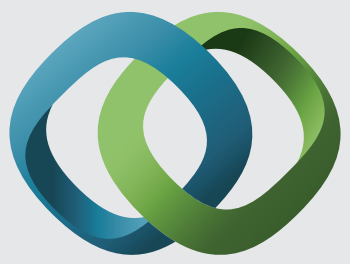

\section{Hindawi}

Submit your manuscripts at

http://www.hindawi.com
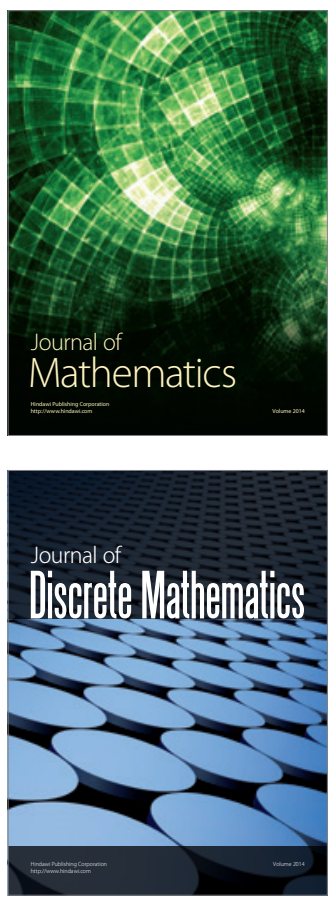

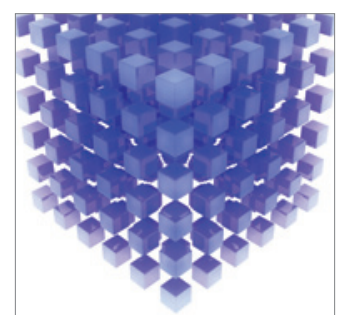

Mathematical Problems in Engineering
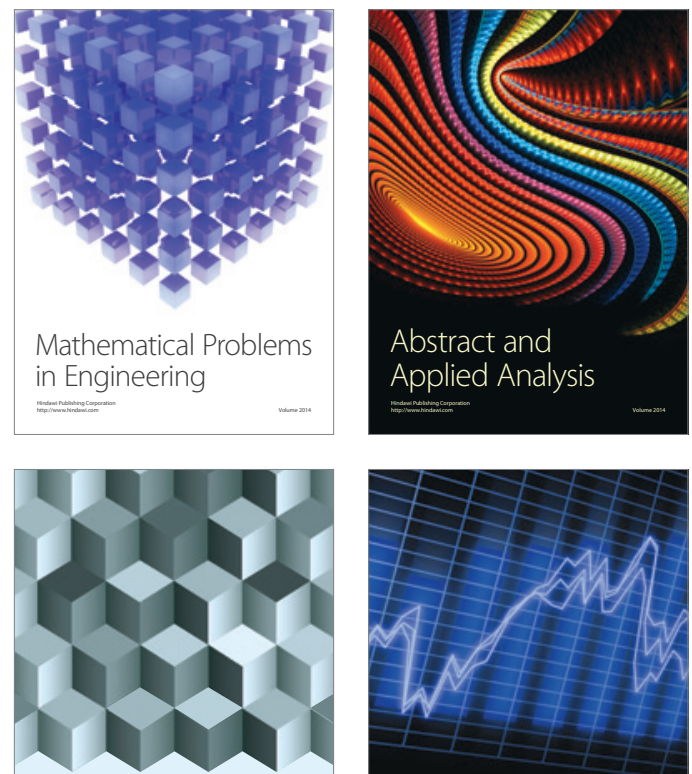

Journal of

Function Spaces

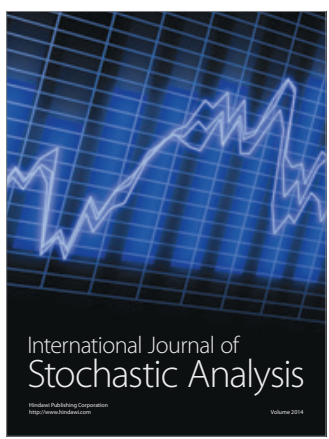

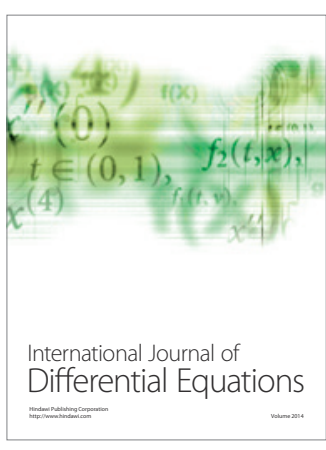
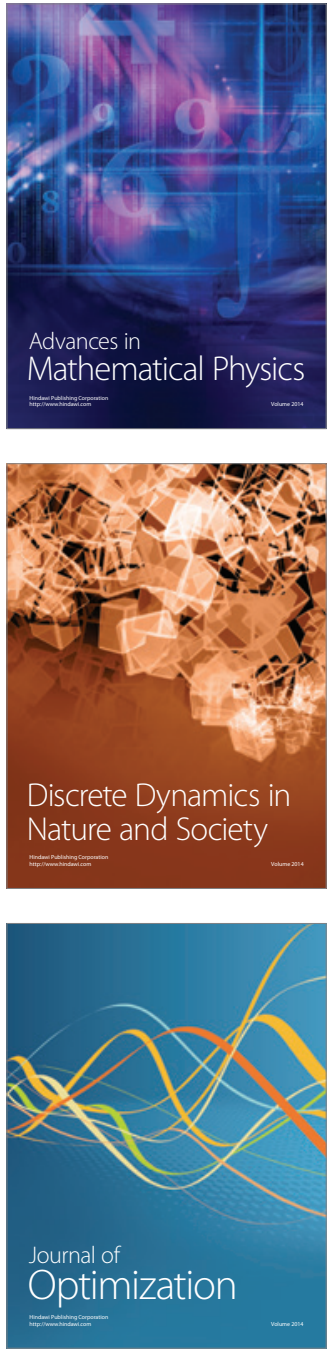